\title{
Review of the hydrodynamic challenges in the design of elevated pile cap foundations for sea-crossing bridges
}

\author{
Kai Wei ${ }^{1 *}$ (D, Cong Zhou ${ }^{1}$, Mingjin Zhang ${ }^{1}$, Zilong Ti ${ }^{1}$ and Shunquan Qin ${ }^{1,2}$
}

\author{
* Correspondence: kaiwei@home. \\ swjtu.edu.cn \\ ${ }^{1}$ Department of Bridge Engineering, \\ Southwest Jiaotong University, \\ Chengdu 610031, China \\ Full list of author information is \\ available at the end of the article
}

\begin{abstract}
With the increasing demand for land transportation in coastal areas, the number of sea-crossing bridges has increased rapidly. In the construction of sea-crossing bridges, the elevated pile cap foundation is one of the most commonly used foundation types. This paper summarizes four main aspects of the research on the hydrodynamic effects on elevated pile cap foundations through timing analysis and keyword co-occurrence analysis. The relevant studies are reviewed from the aspects of waves, currents, and their interactions; the hydrodynamic load on the elevated pile cap foundation; fluid-structure interactions; and the structural responses of bridges that are supported by elevated pile cap foundations. Finally, the following future prospects for hydrodynamic studies of elevated pile cap foundations for the sea-crossing bridge have been discussed, which include wave-current interaction mechanism, wave-current load, fully coupled fluid-structure interactions, and structural dynamic response under hydrodynamic combined with the other hazards.
\end{abstract}

Keywords: Sea-crossing bridges, Elevated pile cap foundation, Hydrodynamic load, Fluid-structure interaction, Dynamic response, CiteSpace

\section{Introduction}

In recent decades, the demand for land transportation in coastal areas of various countries has continued to grow, which has led to a rapid development stage in the construction of sea-crossing bridges (Ti et al. 2019; Zhu et al. 2019). In contrast to land bridges, sea-crossing bridges are in a more complex and variable marine environment, which inevitably suffers from various harsh natural phenomena, such as strong waves, rapid currents, and earthquakes (Guo et al. 2015). This paper collects all the opened design schemes of sea-crossing bridges worldwide in the past 100 years (since 1920) and identifies 121 bridges for which the full span exceeds $5 \mathrm{~km}$. Statistics on their construction times are presented in Fig. 1. Before 2000, there were a total of 38 long-span sea-crossing bridges worldwide. Most of them were located in the United States, Japan, and Denmark. The first sea-crossing bridge was completed in China in 2005. Since then, the construction of sea-crossing bridges in China has entered a rapid development stage. As of October 2020, 58 long-span sea-crossing bridges had been built or

(c) The Author(s). 2020 Open Access This article is licensed under a Creative Commons Attribution 4.0 International License, which permits use, sharing, adaptation, distribution and reproduction in any medium or format, as long as you give appropriate credit to the original author(s) and the source, provide a link to the Creative Commons licence, and indicate if changes were made. The images or other third party material in this article are included in the article's Creative Commons licence, unless indicated otherwise in a credit line to the material. If material is not included in the article's Creative Commons licence and your intended use is not permitted by statutory regulation or exceeds the permitted use, you will need to obtain permission directly from the copyright holder. To view a copy of this licence, visit http://creativecommons.org/licenses/by/4.0/. 


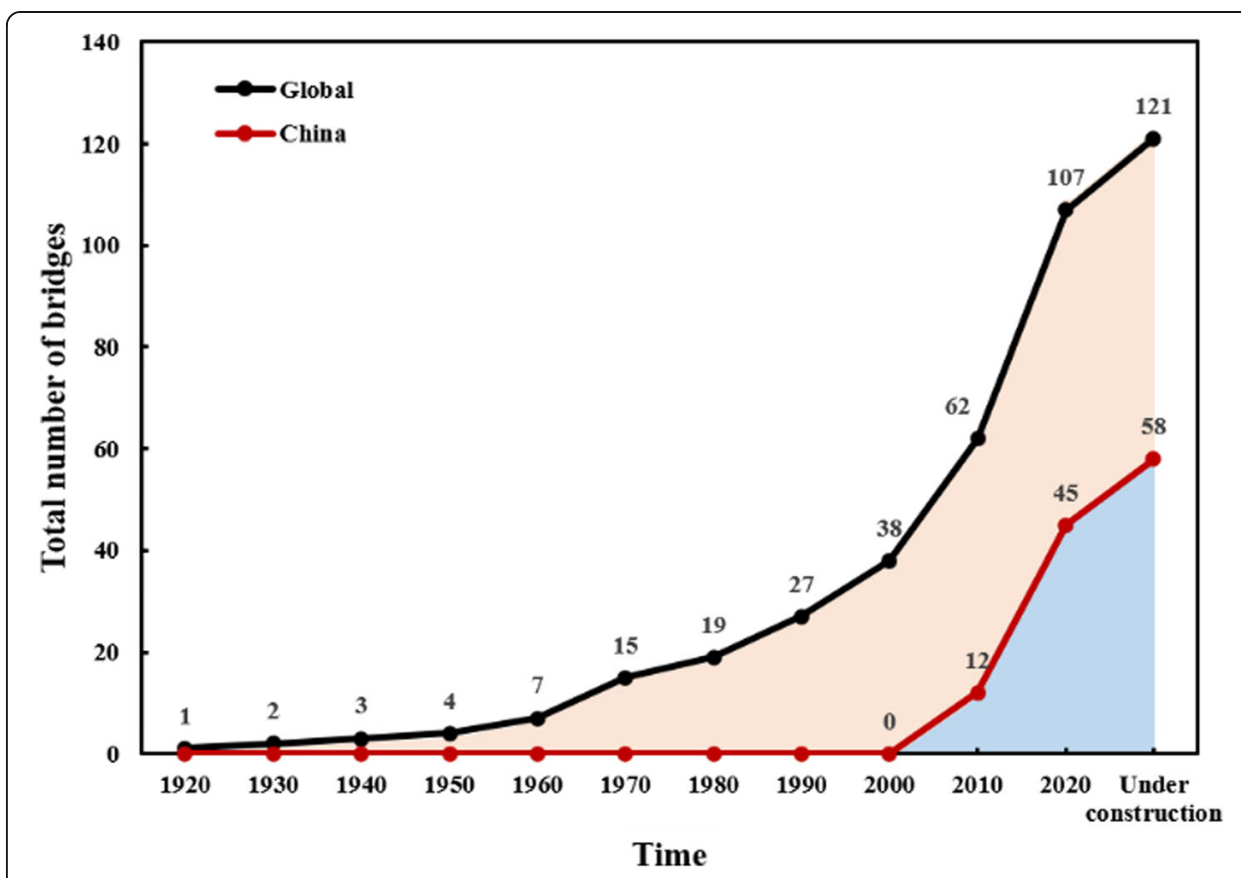

Fig. 1 Statistics on the number of sea-crossing bridges

were under construction in China, which accounted for $47.9 \%$ of the long-span seacrossing bridges globally.

In the construction and development of sea-crossing bridges, pile and caisson foundations are two main foundation types that have been widely used. The application percentages of pile and caisson foundations in the long-span sea-crossing bridges that are under construction are presented in Fig. 2. Among these bridges, 93\% adopted pile foundations.

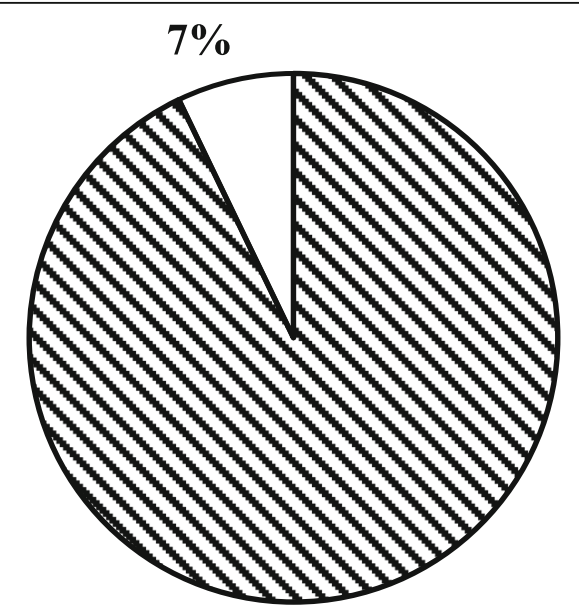

93\%

$\checkmark$ Pile foundation $\square$ Caisson foundation

Fig. 2 Pie chart of the application of pile and caisson foundations in sea-crossing bridges 
The commonly used pile foundations for sea-crossing bridges include a pile group and a pile cap. They can be divided into two types, namely, low and elevated pile cap foundations, according to the elevation of the pile cap from the seabed. A low pile cap foundation is a pile foundation with a cap that is at or below the seabed (Fig. 3b). In contrast, an elevated pile cap foundation has a cap that is above the seabed and usually close to the sea level (Fig. 3c). It has the characteristics of satisfactory geological adaptability, low cost, and convenient construction (Huang et al. 2002). Among the sea-crossing bridges with pile foundations that are under construction, $85 \%$ adopt elevated pile cap foundations, and $15 \%$ adopt low pile cap foundations. Many previously constructed sea-crossing bridges also adopt elevated pile cap foundations, such as Hangzhou Bay Bridge (Cheng et al. 2008), Jiaozhou Bay Bridge (Tian 2010), Hong Kong-Zhuhai-Macao Bridge (Qiu et al. 2013), Pingtan Straits Rail-cum-Road Bridge (Chen and Mei 2016), Donghai Bridge (Chen 2019), Zhoushan Mainland and Islands Link Project (Cui et al. 2019).

As the construction of sea-crossing bridges gradually develops from offshore to deep water, hydrodynamic effects have become critical factors that control the design of seacrossing bridges (Chen et al. 2009) (Fig. 4). For example, the 100-year recurrence wave of the Xihoumen Rail-cum-Road Bridge is as high as $7.8 \mathrm{~m}$, and its 100-year recurrence current velocity reaches $3.32 \mathrm{~m} / \mathrm{s}$. In the Taiwan Strait, waves may reach as high as 12 $m$ (Chen 1981). In addition, the sea-crossing bridge on the eastern coast of China is highly likely to suffer from earthquakes. Under the action of an earthquake, the hydrodynamic effects on the sea-crossing bridge will significantly change the dynamic characteristics and seismic response of the structure, which will exacerbate the damage that is caused by the earthquake.

Damage to the sea-crossing bridge by the extreme marine environment will cause huge economic losses and pose huge challenges in subsequent disaster relief work. Waves and storm surges that were caused by Hurricane Ivan in 2004, Hurricane Katrina in 2005 (Fig. 5a), and Hurricane Ike in 2008 successively destroyed many sea-

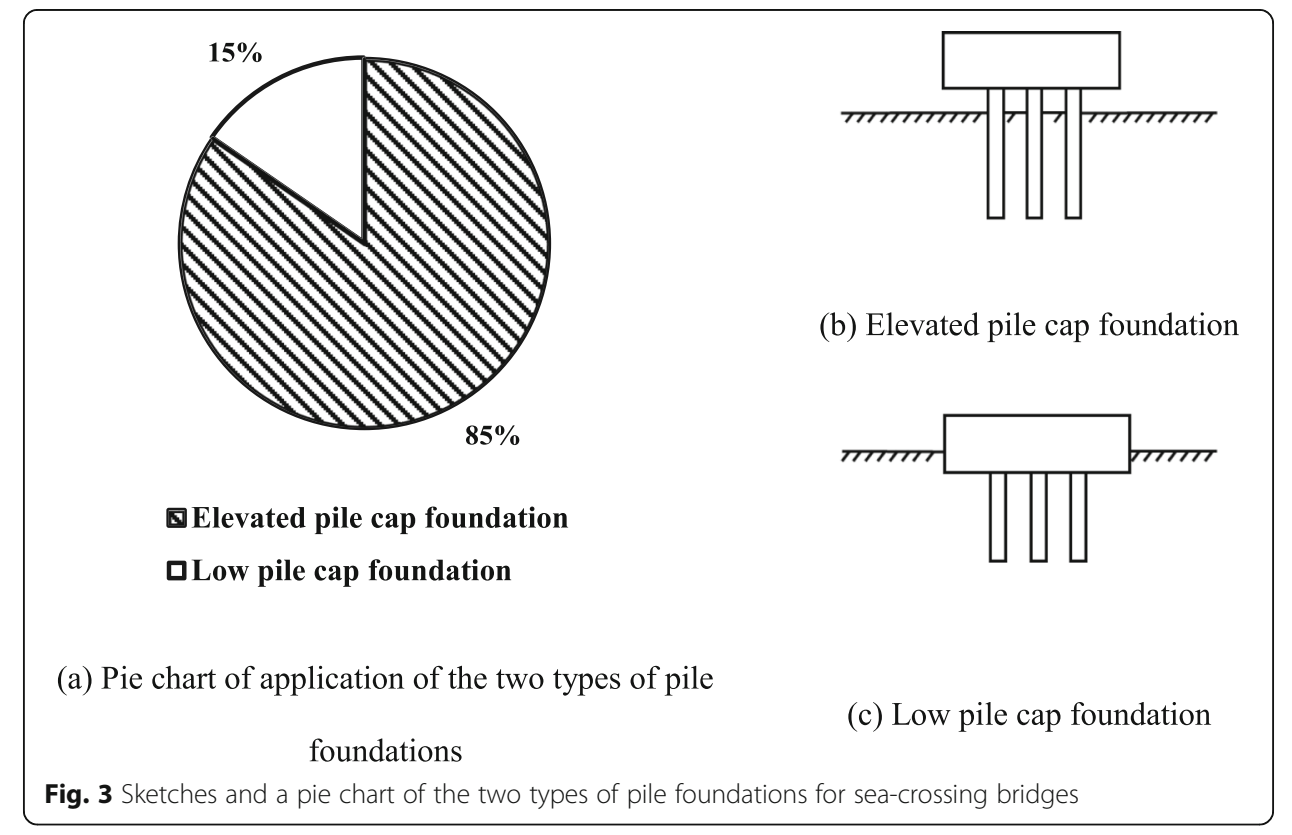



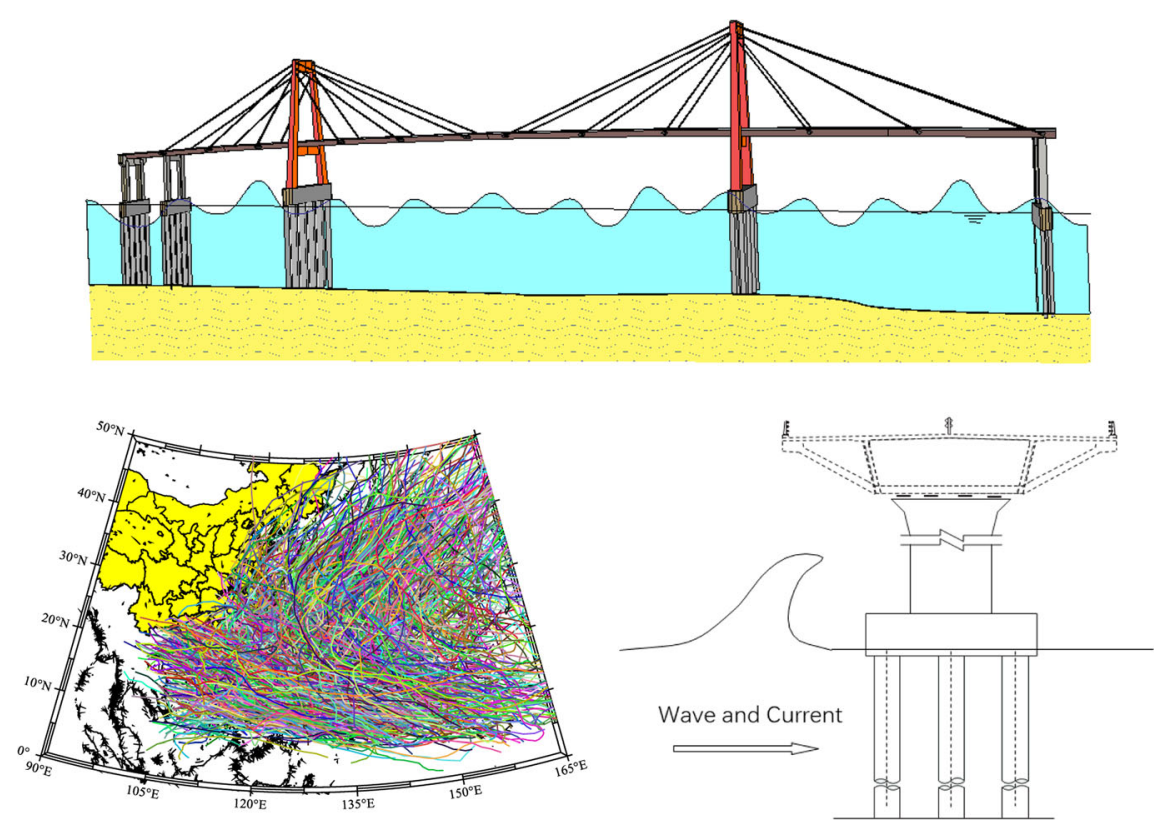

Fig. 4 Hydrodynamic loads on the elevated pile cap foundations of sea-crossing bridges

crossing bridges in the United States (Hang and Xiao 2009; Padgett et al. 2012; Murphy et al. 2009). In Japan, the Hanshin-Awaji-daishinsai in 1995 damaged the Higashi Kobe Bridge and the Akashi Kaikyo Bridge (Chen 2016) (Fig. 5b). Previous accidents have shown that the hydrodynamic effect on the sea-crossing bridge is one of the main factors that causes damage. Therefore, ensuring the structural safety of elevated pile cap foundations under hydrodynamic effects is an important challenge in the development of sea-crossing bridges.

Sea-crossing bridges have been constructed in China for 20 years. Many scholars have conducted detailed studies and reviews on the hydrodynamic effects on the superstructure of sea-crossing bridges (Fang 2012; Xu and Cai 2015). However, few researchers have conducted in-depth reviews on the hydrodynamic effects on elevated pile cap foundations. This paper uses the CiteSpace software to conduct a dynamic analysis of the literature on the hydrodynamic effects on elevated pile cap foundations over the past two decades. The development route and current scenario are examined, and the

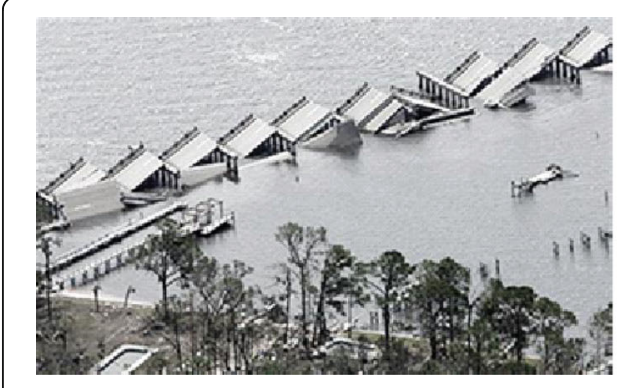

(a) Damaged offshore bridges during Hurricane Katrina

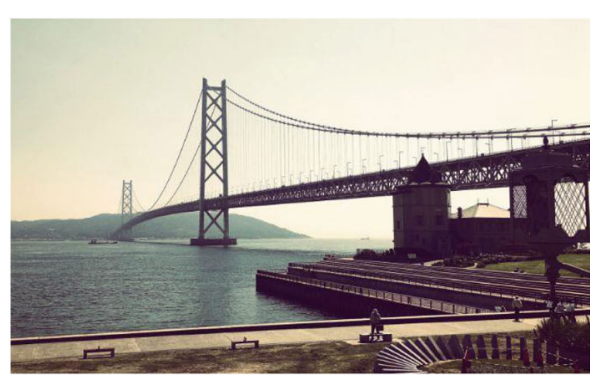

(b) Akashi Kaikyo Bridge built after the earthquake

Fig. 5 Damage to sea-crossing bridges that was caused by hydrodynamic effects 
research focus and direction are summarized. Finally, prospects in the future investigation of hydrodynamic effects on elevated pile cap foundations are discussed.

\section{Literature analysis of the research on hydrodynamic effects on elevated pile cap foundations}

This paper used an information visualization tool, namely, CiteSpace (Chen 2006), to conduct a literature visualization analysis of the knowledge graph of the research on the hydrodynamic effects on elevated pile cap foundations over the past two decades. Relevant studies from January 1, 2000 to November 10, 2020 were collected from the databases of the Web of Science (website: http://apps.webofknowledge.com/) and the China National Knowledge Infrastructure (website: https://www.cnki.net/) using keywords such as wave, current, wave-current, pile, pile cap, dynamic response, seismic, and earthquake. After removing the duplicates, 283 papers were selected for the literature analysis.

\subsection{Timing analysis}

A timing analysis can identify the development trend of research on the hydrodynamic effects on elevated pile cap foundations. This paper counted the number of relevant publications each year in the literature, and the results are plotted in Fig. 6. The annual number of publications showed an overall upward trend and reached a small peak in 2010. The research on the hydrodynamic effects on elevated pile cap foundations can be divided into three stages: The first stage is from 2000 to 2008, which is the initial stage, and the studies focus mainly on waves, current forces, and pile group effects. The total number of papers in this stage is 77. The second stage is from 2008 to 2012, during which a small peak appeared. Waves, computational fluid dynamics (CFD), and wave-current interactions are the research focuses at this stage. The stage after 2012 is a period of rapid development in the research on hydrodynamic effects on elevated pile

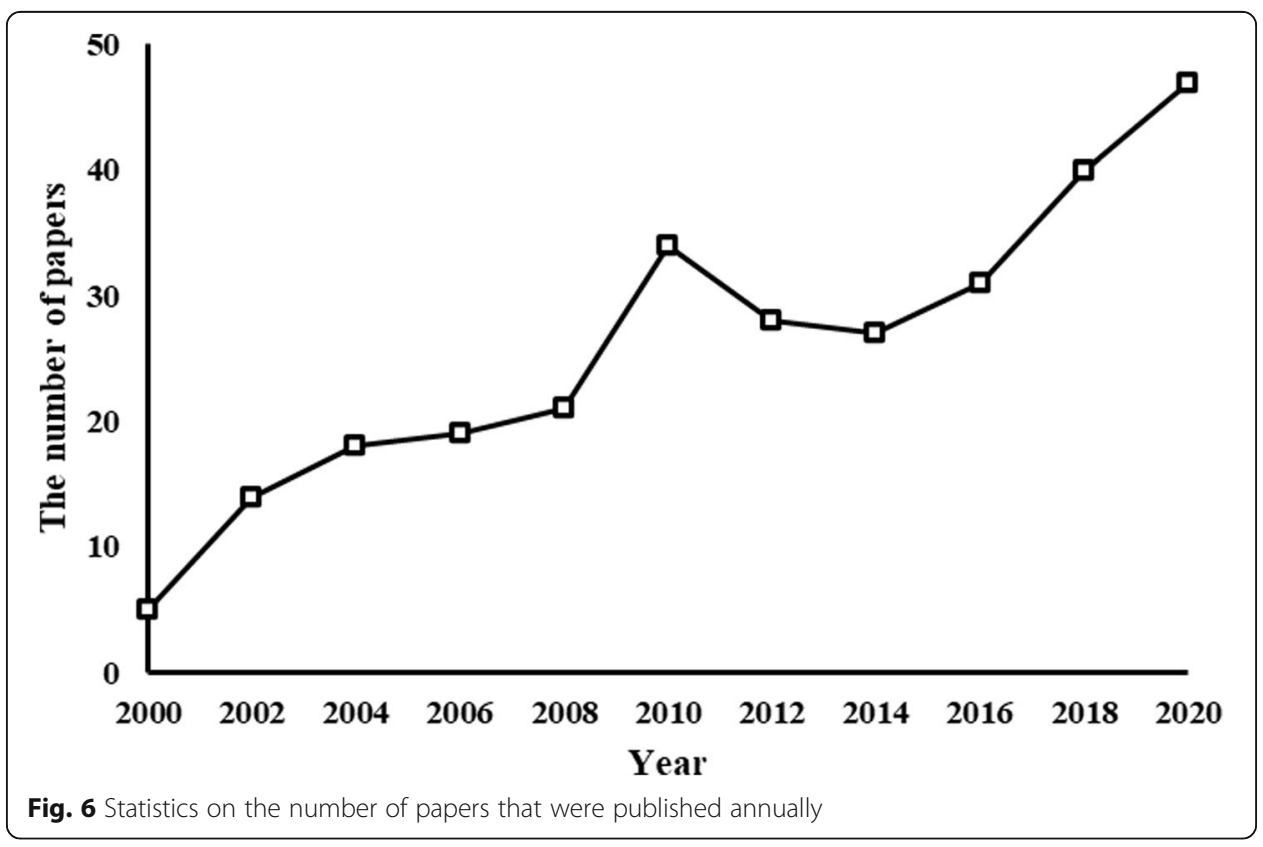


cap foundations. The research focus has gradually shifted to fluid-structure interactions, the finite element method, and the dynamic response. According to the timing analysis results, the hydrodynamic effects on elevated pile cap foundations are receiving increasing attention.

\subsection{Keyword co-occurrence analysis}

Keyword co-occurrence analysis can be used to identify the research focus and direction (Chen 2006). This paper analysed the relevant literature on the hydrodynamic effects of elevated pile cap foundations and identified the keyword co-occurrence network, which is illustrated in Fig. 7. Table 1 lists the high-frequency keywords and high-centrality keywords in the keyword co-occurrence network.

The keywords with a high frequency of co-occurrence include "Sea-crossing bridges", "Fluid-structure interaction", "Wave", and "Finite element method", among other keywords. Among them, "Wave force" and "Current force" correspond to the research direction of hydrodynamic load; "Fluid-structure interaction" and "Dynamic response" correspond to the research direction of fluid-structure interaction; and "Finite element method" and "CFD" correspond to the research direction of numerical simulation. These keywords reflect scholars' investigations of the hydrodynamic effects on elevated pile cap foundations from various aspects.

The betweenness centrality is an indicator that measures the importance of a node in the knowledge graph and indicates the significance of papers. According to Table 1, "Wave force", "Finite element method", "Sea-crossing bridges", "Wave-current interaction", and "Wave-current force", among other keywords, have high betweenness

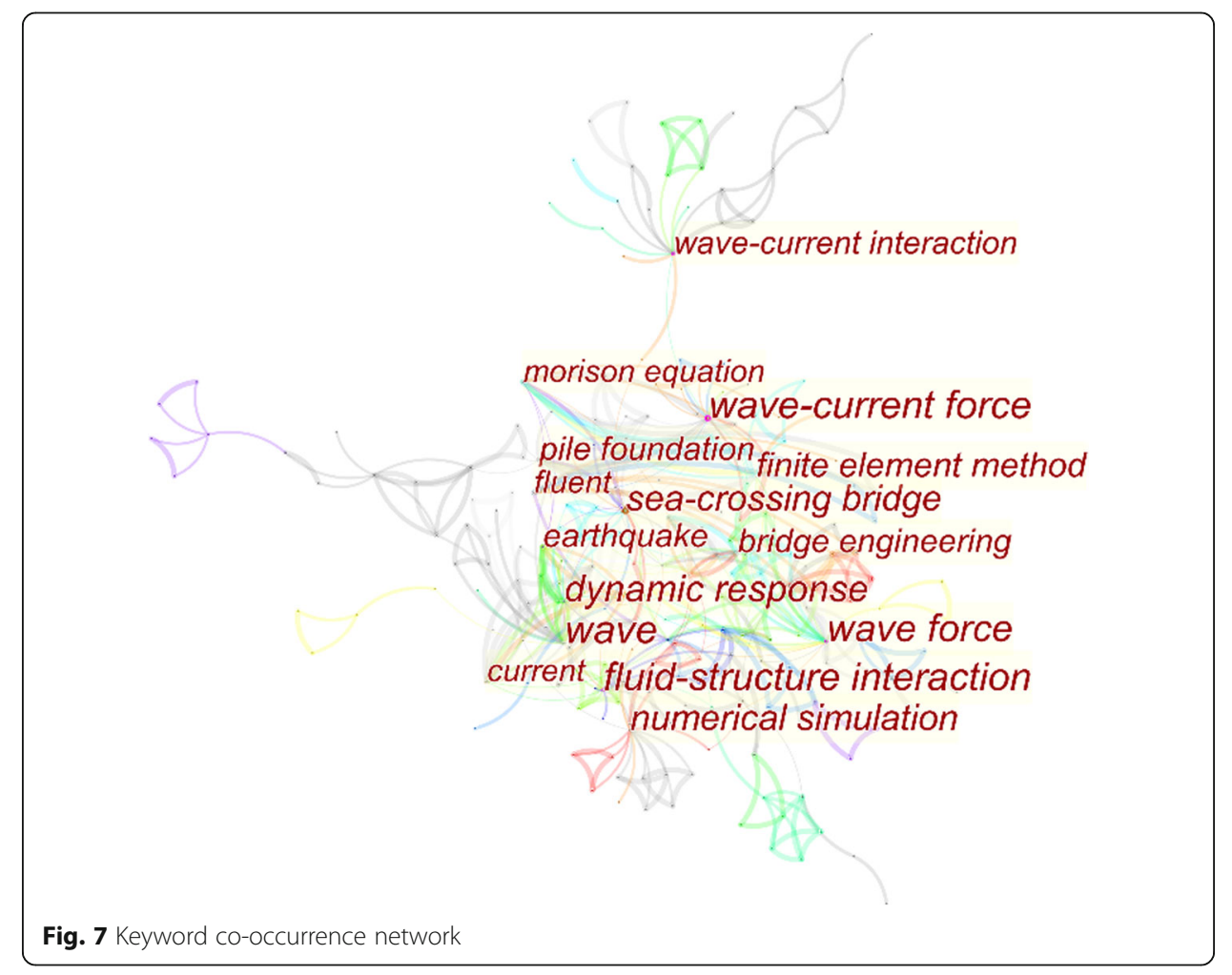


Table 1 High-frequency keywords and high-centrality keywords for the hydrodynamic effects of elevated pile cap foundations

\begin{tabular}{|c|c|c|c|c|c|}
\hline \multicolumn{3}{|l|}{ High-frequency Keywords } & \multicolumn{3}{|l|}{ High-centrality Keywords } \\
\hline Keyword & Frequency & $\begin{array}{l}\text { Betweenness } \\
\text { centrality }\end{array}$ & Keyword & Frequency & $\begin{array}{l}\text { Betweenness } \\
\text { centrality }\end{array}$ \\
\hline Sea-crossing bridge & 63 & 0.23 & Wave force & 18 & 0.24 \\
\hline Fluid-structure interaction & 35 & 0.24 & Fluid-structure interaction & 35 & 0.24 \\
\hline Wave & 34 & 0.18 & Sea-crossing bridge & 63 & 0.23 \\
\hline Finite element method & 28 & 0.15 & Wave-current interaction & 13 & 0.23 \\
\hline Bridge engineering & 26 & 0.07 & Wave-current force & 9 & 0.21 \\
\hline Pile cap & 25 & 0.04 & Wave & 34 & 0.18 \\
\hline Current force & 23 & 0.03 & Pile foundation & 20 & 0.16 \\
\hline CFD & 23 & 0.01 & Finite element method & 28 & 0.15 \\
\hline Pile foundation & 20 & 0.16 & Numerical & 10 & 0.15 \\
\hline Wave force & 18 & 0.24 & Dynamic response & 16 & 0.11 \\
\hline Dynamic response & 16 & 0.11 & Morison equation & 8 & 0.11 \\
\hline
\end{tabular}

centrality, which are research focuses. Cluster analysis is applied to the keywords to obtain the cluster label words, such as "Wave", "Fluid-structure interaction", "Time-domain simulation", "Wave force", and "Sea-crossing bridge". By comprehensively analysing the results of the timing analysis, keywords co-occurrence analysis, and cluster analysis, the research on the hydrodynamic effects on elevated pile cap foundations can be reviewed from the following four aspects: waves, currents and their interactions; the hydrodynamic load on the elevated pile cap foundation; fluid-structure interaction; and the structural responses of bridges that are supported by elevated pile cap foundations.

\section{Waves, currents and their interaction}

Waves and ocean currents are common phenomena in nature (Fig. 8). The propagation of waves in the ocean is always accompanied by ocean currents (Wang and Li 1999). The interaction between them is a complex nonlinear process. When a wave-current acts on an elevated pile cap foundation, the hydrodynamic load cannot be calculated by simply summing the wave load and the current load linearly (Ren 1983). Thus, the investigation of waves, currents, and their interaction is highly necessary.

\subsection{Wave theory}

Wave theory can be divided into linear wave theory and nonlinear wave theory (Wang and Liang 1991). Linear wave theory assumes that the wave height is infinitely small relative to the wavelength and that the water particles move slowly. Therefore, the nonlinear effect of the free surface can be ignored, and the boundary conditions can be simplified to linear conditions. However, the wave height in the actual marine environment is often as high as several metres to tens of metres. The nonlinear effect of the free surface cannot be ignored.

Abandoning the assumption that the wave height is infinitely small relative to the wavelength, Stokes proposed the Stokes wave theory, which considers the nonlinear effect of the free surface. This theory considers the influence of the wave steepness and 

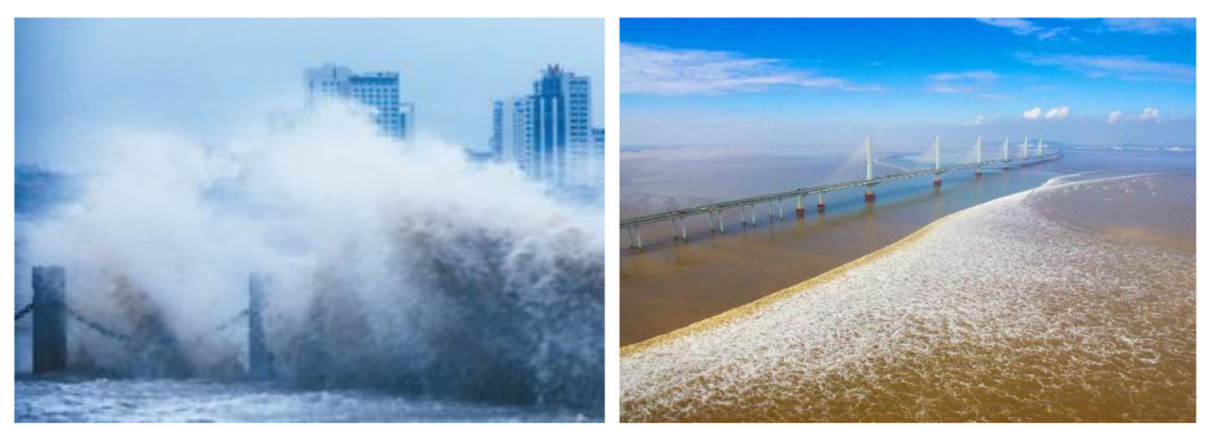

Fig. 8 Wave and current in the ocean

regards it as the main factor that determines wave propagation (Stokes 1847). Based on the study of Strokes, Michael et al. proposed the second-order Stokes wave theory in 1945. Then, Skjelbreia successively proposed the third-order Stokes wave theory and the fifth-order Stokes wave theory in 1958 and 1961, respectively (Sarpkaya et al. 1982; Ma and Zhao 2002; Larmaei and Mahdi 2010).

When a wave propagates offshore, the Stokes wave theory no longer satisfies the accuracy requirements for describing wave propagation due to the frictional drag of the seabed. In 1895, Korteweg and de Vries used the Jacobian elliptic cosine function $c n$ to describe the wave propagation and proposed the Cnoidal wave theory (Korteweg and de Vries 1895). This theory is one of the most important shallow water nonlinear wave theories. Based on the Cnoidal wave theory, Korteweg and de Vries derived the analytical solution for solitary waves (Korteweg and de Vries 1895). A solitary wave can be regarded as an extreme case of a Cnoidal wave. It is an advanced wave in which the water particles only move along the direction of wave propagation.

For the wave theories that are discussed above, Méhauté and Bernard (2013) used two dimensionless independent parameters, namely, $H / g T^{2}$ and $d / g T^{2}$, to specify the applicable ranges of each wave theory, as illustrated in Fig. 9. In addition, the stream function wave theory (Dean and Dalrymple 1991) and many other modern theories that have been established and applied to numerical simulations (Andrzej et al. 2008; Kriebel 1998; Lewis 1997; Palma et al. 2006).

\subsection{Current profile}

The most common ocean currents are tidal currents, wind-generated currents, circulational currents, loop and eddy currents, soliton currents, and longshore currents. In engineering practice, a current can be regarded as a stable flow field in which the current velocity vector is only a function of the depth. According to the DNV-RP-C205 (Veritas 2010), the total current velocity at a position $(x, y)$ should be expressed as the vector sum of each current component:

$$
V_{c}(z)=V_{c, \text { wind }}(z)+V_{c, \text { tide }}(z)+V_{c, \text { ric }}(z)+\ldots \ldots
$$

When detailed field measurements are not available, the current can be assumed to be unidirectional, and the variation of the tidal current velocity in shallow water with the depth can be modelled using a simple power-law function (Fig. 10a). 


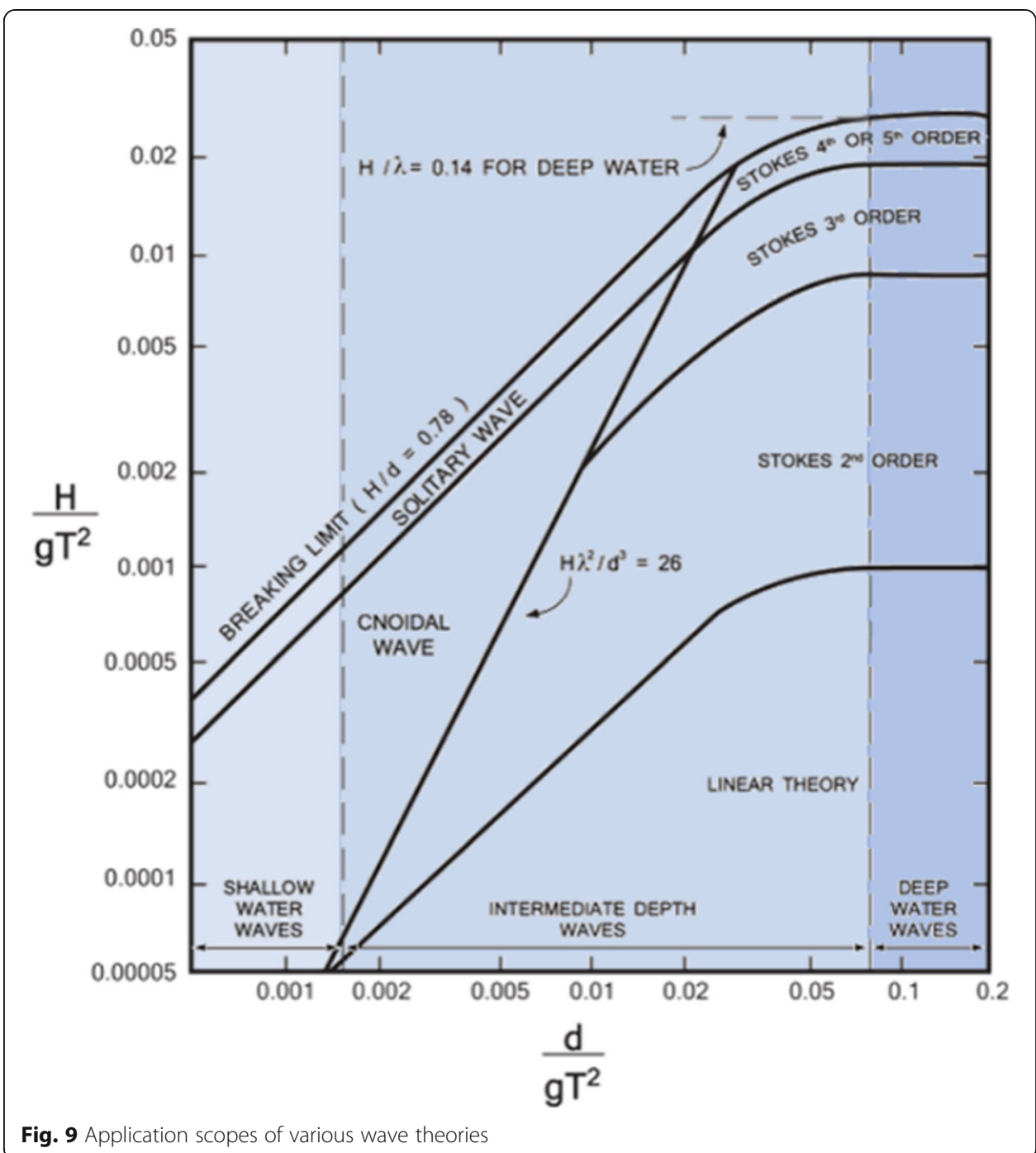

$$
V_{c, t i d e}(z)=V_{c, t i d e}(0)\left(\frac{d+z}{d}\right)^{\alpha} \text { for } z \leq 0
$$

The variation of a wind-generated current can be regarded as a linear profile (Fig. 10b) from $z=-d_{0}$ to the still water level or as a slab profile (Fig. 10c).

$$
V_{c, \text { wind }}(z)=V_{c, \text { wind }}(0)\left(\frac{d_{0}+z}{d_{0}}\right) \text { for }-d_{0} \leq z \leq 0
$$

or

$$
V_{c, \text { wind }}(z)=V_{c, \text { wind }}(0) \text { for }-d_{0} \leq z \leq 0
$$

It can be assumed that wind-generated currents vanish at a distance below the still water level.

$$
V_{c, \text { wind }}(z)=0 \text { for } z<-d_{0}
$$

where $V_{c}(z)$ is the total current velocity at level $z, z$ is the distance from the still water 


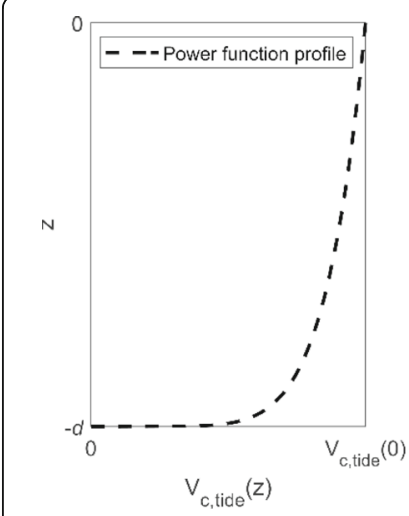

(a) power function profile

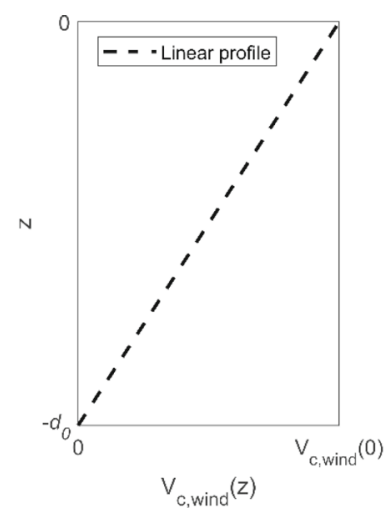

(b) linear profile

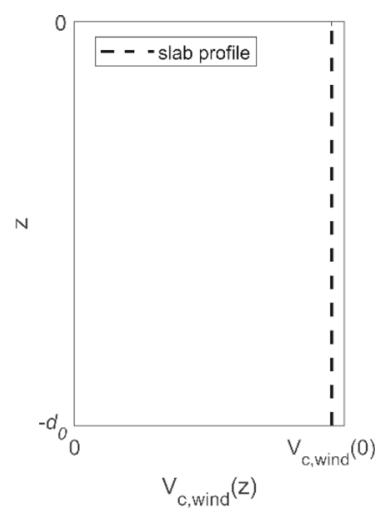

(c) slab profile

Fig. 10 Current velocity profiles

level or the positive upwards distance, $V_{c \text {, tide }}(0)$ is the tidal current velocity at the still water level, $V_{c \text {, wind }}(0)$ is the wind-generated current velocity at the still water level, $d$ is the water depth to the still water level (taken positive), $d_{0}$ is the reference depth for the wind-generated current and $d_{0}=50 \mathrm{~m}$, and $\alpha=1 / 7$.

In the deep water along an open coastline, the wind-generated current velocities at the still water level can be expressed as follows:

$$
V_{c, \text { wind }}(0)=k U_{1 \text { hour }, 10 \mathrm{~m}} \text { where } k=0.015-0.03
$$

where $U_{1 \text { hour, } 10 \mathrm{~m}}$ is the 1 -h sustained wind speed at height of $10 \mathrm{~m}$ above sea level.

\subsection{Wave-current interaction}

The interaction between waves and currents is highly complicated. Many scholars have investigated the wave-current interaction from the perspectives of flow field characteristics and wave parameter changes. Kemp and Simons $(1982,1983)$ examined the velocity distribution of the wave-current field. The results demonstrated that when the wave and current are in the same direction, the velocity of the upper water particles increases while the velocity of the lower water particles decreases. When the wave and current are reversed, the opposite is true. Ren (1983) conducted an experimental study to observe wave particles' movement in which a liquid tracer was added to a wavecurrent flume. As shown in Fig. 11, the velocity of the wave particles in the current is highly consistent with the Airy wave theory in static water. It is suggested that if the wave propagates to a uniform current, only the wave parameters change, and the wave

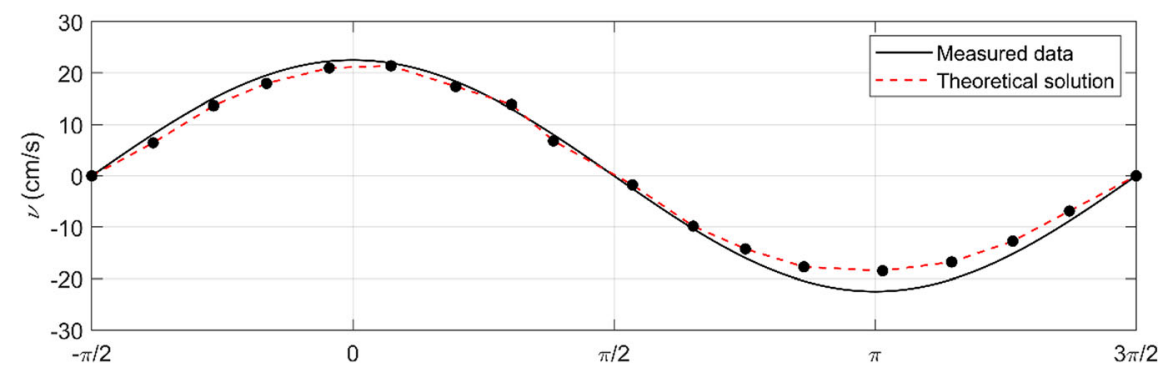

Fig. 11 Comparison of measured wave particle velocity data with the Airy wave theory solution 
theory in static water remains applicable to the uniform current. Li and Ren further analysed the velocity field of wave-current interaction through physical experiment and theoretical derivation, respectively (Li 1983; Ren 1983). The results demonstrated that the horizontal velocity of the water particles in the wave-current field could be obtained by superimposing the original uniform current velocity and wave particle velocity in the current.

The current studies on the variation of wave parameters in currents can be divided into two categories: regular waves and irregular waves. In the 1860s, Longuet-Higgins and Stewart (1961) derived the perturbation solution of a linear wave in an oppositely non-uniform current according to the principle of wave energy flux conservation. Then, Brevik conducted experiments on rough and smooth beds to examine the variation of the wavelength and wave height of a regular wave against a uniform current (Brevik and Bjørn 1979; Brevik and Luftkrigsskolen, Trondheim 1980). Considering the nonlinear effects of waves, Thomas investigated the interactions of an irrotational current with a linear wave and a nonlinear wave (Thomas 1981, 1990). Li (1982) proposed a calculation formula for the wavelength and wave height of a third-order Stokes wave in a uniform current based on wave energy flux conservation and wave action flux conservation. Considering the nonlinearity of the velocity distribution, Wang and Li (1996) proposed a fifth-order theory for solving for the interaction between a Stokes wave and an exponential profile current.

With the development of computers, numerical simulation is widely used in the study of wave-current-structure interactions. Accurate simulation of the wave-current field is the key problem that must be solved before conducting such investigations. As illustrated in Fig. 12, there are three methods for wave-current interaction simulation: The first is the velocity superposition method, which linearly superimposes the horizontal velocities of wave particles and the current at the velocity boundary (Fig. 12a) (Park et al. 2001; Li and Lin 2010). At this time, the wave parameters after the interaction of the wave and current should be used. In 2012, Wei (2012) established a threedimensional numerical flume based on the velocity superposition method and simulated the interaction between the second-order Stokes wave and the current. Qin et al. (2013) used this method to simulate the interactions between waves and currents with various velocity profiles.

Via comparison with the experimental results, the accuracy of the numerical simulation is demonstrated. The second method is to create waves at the entrance boundary

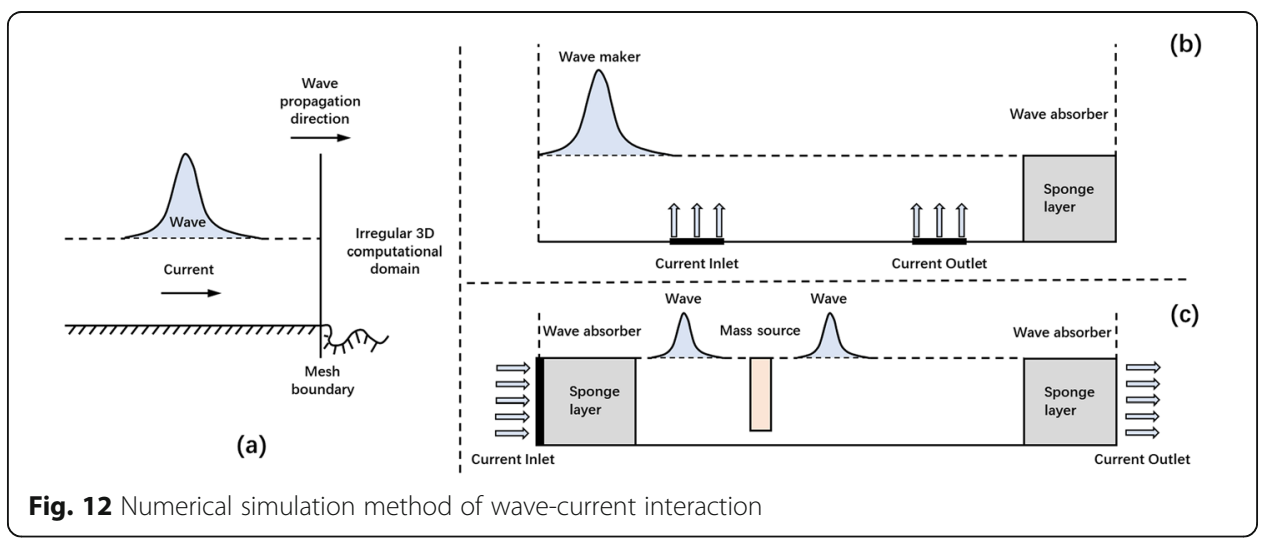


and add currents to the calculation domain to simulate wave-current interactions (Fig. 12b). Xiao et al. (2013) imitated the experimental method and added a current inlet and a current outlet at the bottom of the calculation domain for wave-current interaction simulation. In the third method, the current inlet is set at the entrance boundary, and a mass source is used to generate waves in the calculation domain (Fig. 12c). Zhang and Ding used this method to establish two-dimensional and threedimensional models, respectively, of the interactions between regular waves and currents (Zhang et al. 2014; Ding et al. 2015).

These numerical simulation methods are limited mainly to the interactions between regular waves and currents. Few numerical simulation methods are available for the interactions between irregular waves and currents.

\section{Hydrodynamic load on the elevated pile cap foundation}

A sea-crossing bridge is in a complex and variable marine environment, which inevitably suffers from various harsh natural phenomena, such as waves, currents, and their combined effect. As the construction of sea-crossing bridges gradually develops from offshore to deep water, these hydrodynamic effects have become the critical factors that control the design of sea-crossing bridges (Fig. 13). Therefore, the accurate calculation of the hydrodynamic load on elevated pile cap foundations is important for guaranteeing the safety of sea-crossing bridges.

\subsection{Wave load}

\subsubsection{Wave load on the pile group}

For the calculation of the wave load on an offshore structure, various methods should be adopted according to the ratio of the structure size to the wavelength. The pile of the elevated pile cap foundation usually has a small geometric size and is a small-scale structure $(D / L<0.2$, where $D$ is the diameter of the pile and $L$ is the wavelength). This structure has no readily observable effect on wave propagation. The Morison equation

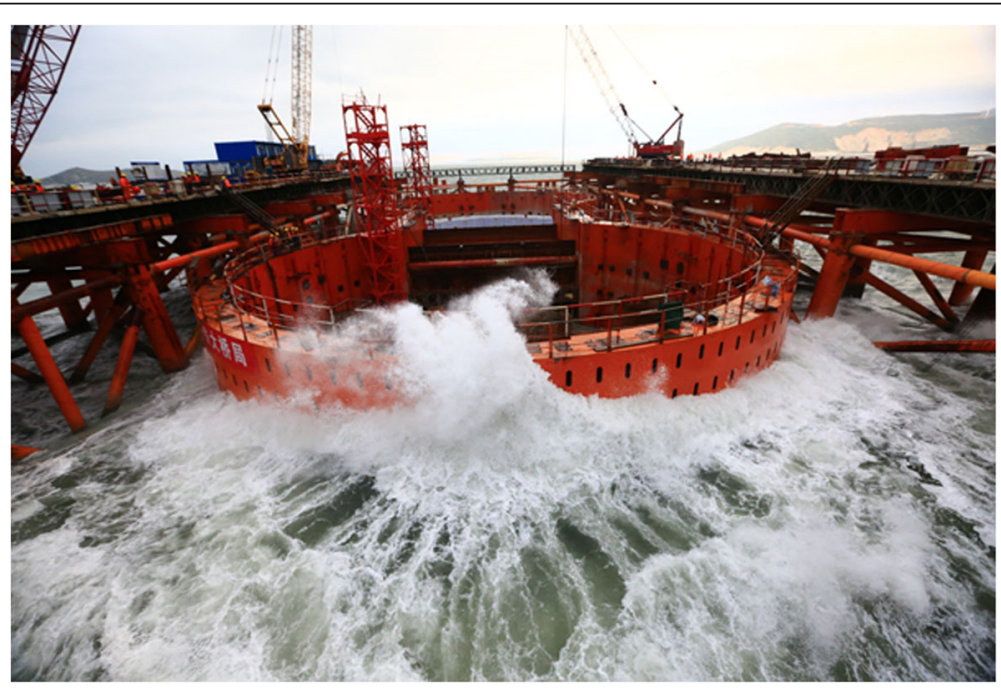

Fig. 13 Hydrodynamic load on the cofferdam of an elevated pile cap foundation 
is usually used to calculate its wave load (Liu et al. 2020) (Fig. 14). According to the Morison equation, the horizontal wave load that acts at any height of the column includes two components: the drag force $f_{D}$ and the inertial force $f_{M}$. The wave load per unit length of a vertical cylinder at any height can be expressed as:

$$
f_{H}=f_{D}+f_{M}=\frac{1}{2} \rho C_{d} A|u| u+\rho C_{m} V_{0} \frac{d u}{d t}
$$

where $u$ and $\frac{d u}{d t}$ are the velocity and acceleration, respectively, of the water particle on the axis of the cylinder; $C_{d}$ is the drag force coefficient; $C_{m}$ is the inertial force coefficient; $A$ is the projected area of the unit cylinder height perpendicular to the wave propagation direction; $V_{0}$ is the volume of cylinder per unit height; $\rho$ is the fluid density.

The calculation of the wave load on a pile group differs substantially from that of the wave load on a single pile. The mutual influence between component piles, such as the phase difference (Fig. 15a), interference effect, and shadowing effect (Fig. 15b), cannot be ignored (Andrzej and Ryszard 2008).

Before 2000, the study of the pile group effect focused only on four pile arrays at most. However, the pile group foundation of a sea-crossing bridge is far more complicated than this. In 2009, Yao and Liu (2009) considered a nine-pile array pile foundation as the study object to investigate the pile group effect that is caused by the phase difference. The results demonstrated that the pile group effect that is caused by the phase difference decreases with the increase of the pile spacing and fluctuates with the wave incident angle change.

The influences of the interference effect and the shadowing effect on the pile group are highly complicated. They are usually considered by the pile group coefficient (the ratio of the wave force of each component pile to that of a single pile). Through a physical model test, Lei (2013) investigated the pile group effect of a five-pile structure under the action of regular waves and irregular waves. This study focused on the load

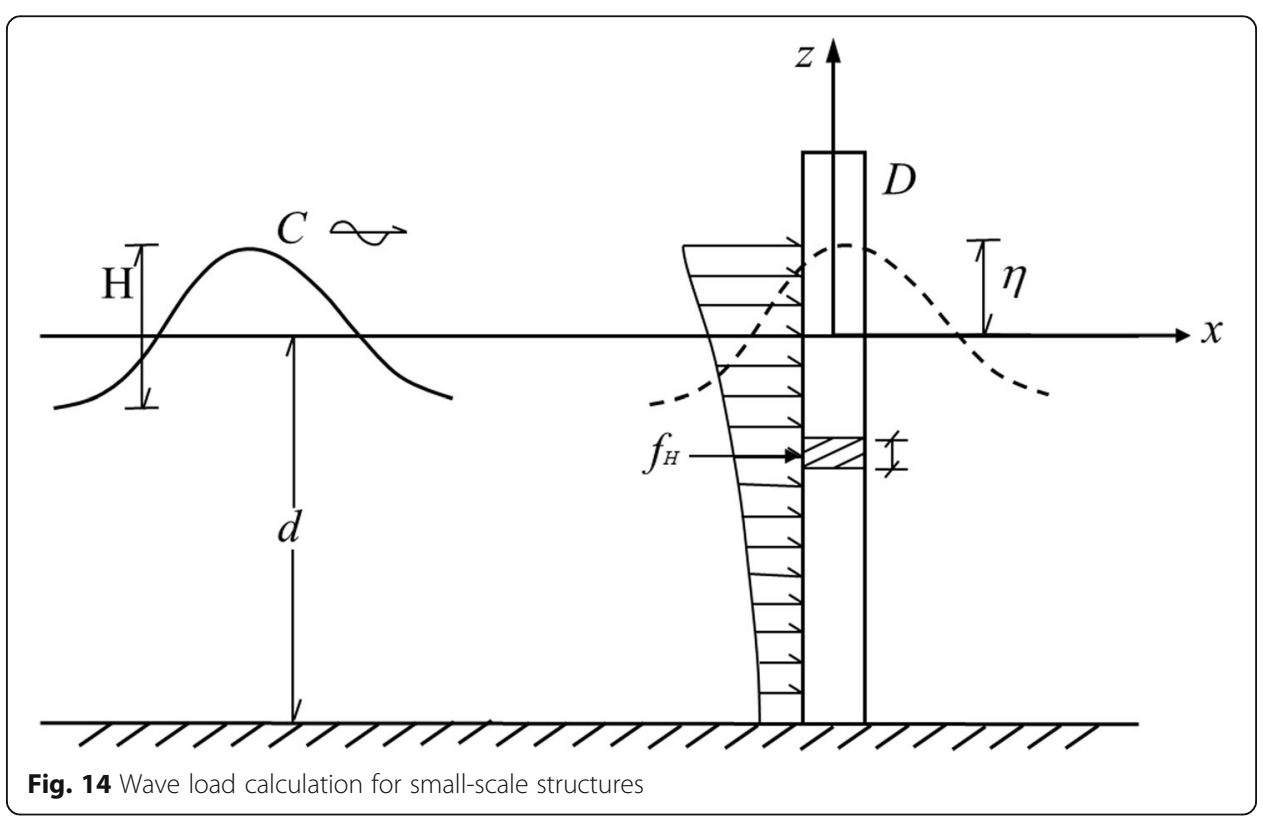




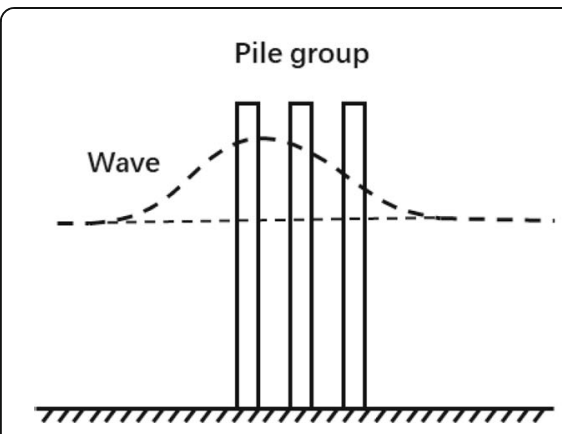

(a) phase difference

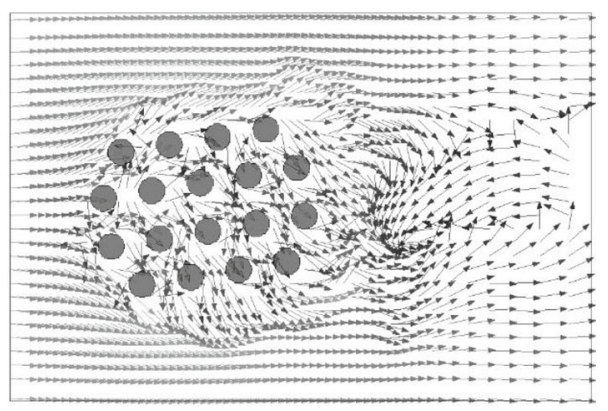

(b) interference effect and shadowing effect

Fig. 15 Pile group effect

on each component pile and its proportion in the total load when the wave load on the pile group reached the maximum. In 2018, Zhang et al. (2018) examined the action of multi-directional irregular waves on nine piles in a side-by-side arrangement through physical model experiments. The relationships of the inline force and the transverse force with the $K C$ number and the relative pile spacing are analysed. On this basis, Zhang et al. (2019a, b) investigated the variations of the pile group coefficients of the inline force and the transverse force with the relative pile spacing and the $K C$ number. The pile group coefficient of each pile in the pile group was compared. Regarding the geometrically asymmetrically pile-supported structures as the research objects, Li et al. (2019) proposed two geometric parameters, namely, the asymmetry coefficient and the area ratio of the structure, which expanded the application scope of the empirical formula for wave force calculation. Subsequently, Li et al. (2020) investigated the wave load on geometrically asymmetrically pile-supported structures with six pile spacings and four alignment angles. The empirical formula for the dimensionless wave force was modified, and the pile group coefficient of geometrically asymmetrically pile-supported structures was obtained.

At present, the semi-empirical and semi-theoretical Morrison equation remains the main method for calculating the wave load on the pile group. The interference effect and shadowing effect are mainly considered by the pile group coefficient. However, the understanding of the interaction mechanism between the pile group and wave remains insufficient.

\subsubsection{Wave load on the pile cap}

The pile cap of a sea-crossing bridge is usually a large-scale structure $(D / L>0.2)$. The reflection and diffraction of waves around it cannot be ignored. Therefore, for the calculation of the wave load on the pile cap, diffraction theory is typically adopted. Li et al. (2017) used the Morison equation, diffraction theory, and the CFD method to calculate the wave loads on pile caps of various relative scales. The results demonstrated that diffraction theory and the CFD method are applicable to the calculation of wave loads on large-scale structures. The interaction between waves and structures involves not only a diffraction force but also a radiation force that is generated by structural oscillations. Adopting the three-dimensional potential flow theory in consideration of the effect of the radiation force, Qiu and Zhao (2019) investigated the variation of the wave 
load of a pile cap with the wave period, draft, and wave direction. Considering the influence of the fluid viscosity, Dong et al. (2020) established a three-dimensional numerical wave flume with the Fluent software, conducted a numerical simulation of a largescale pile cap under wave action, and analysed the influence of the wave height, submerged depth, period, and pile cap size.

An elevated pile cap is located near the still water level and often suffers from significant wave impact. Wave impact at the pile cap involves wave breaking, strong nonlinearity, and other complicated factors (Xu et al. 2020) (Fig. 16). Diffraction theory is no longer applicable. In 1995, Suchithra and Koola (1995) proposed a formula for calculating the wave impact load that acts on offshore platforms based on experiments. It can be expressed as:

$$
F_{s}=\frac{1}{2} \rho A_{s} C_{s} u^{2}
$$

where $F_{s}$ is the impact pressure, $\rho$ is the fluid density, $A_{s}$ is the stressed area, $C_{s}$ is the impact coefficient, and $u$ is the water particle velocity.

AASHTO, API, and DNV all use this method to calculate the wave impact load. The results demonstrated that the impact coefficient is related to the wave period and the clearance between the pile cap and the still water level. Considering various pile caps, Wang and Ren analysed the influences of the wave height, wave period, clearance, and other factors on the wave impact load and fitted an empirical formula for the peak pressure (Ren and Wang 1999, 2003; Ren et al. 2006). Experimentally, Ding et al. (2008) investigated the impact pressure distribution characteristics of the bottom of an open three-dimensional structure and the variation of the impact pressure with related influencing factors. Lan et al. (2010) examined the distribution of the impact pressure on the bottom of a pile cap and determined the variation of the impact pressure with the wave period, wave steepness, and the relative clearance. Using the FLOW-3D software, Xu and Wei (2019) established a three-dimensional numerical model of the interaction between waves and an elevated pile cap and analysed the characteristics of wave
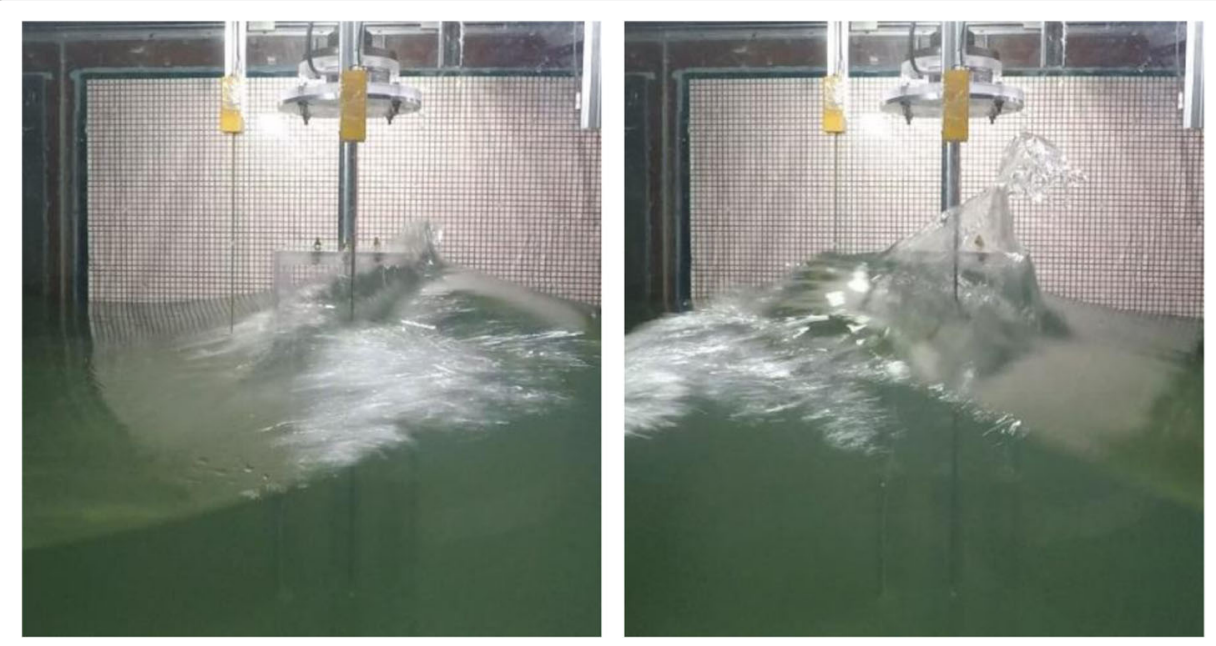

Fig. 16 Photographs of a wave impact cap test 
loads. The pressure distribution on the bottom of the elevated pile cap and the influence of the clearance height on the wave load were examined.

Considering the time-varying characteristics of the wave impact load, Sihouette modified the calculation formula of the wave impact load to include time variables (Raaij and Gudmestad 2007). According to the experimental results and nonlinear potential flow theory, Wienke and Oumeraci (2005) divided the impact process into two stages and established calculation formulas for each stage. In 2007, Raaij and Gudmestad (2007) fitted numerical simulation results and proposed a three-segment model of the wave impact load time history of offshore platforms (Fig. 17a). Analysing the normalized wave impact load time history, Wei et al. (2020) established a time history model of the impact load in which the rising part is a composition of trigonometric functions and the falling part is a power function (Fig. 17b).

Although many scholars have investigated the time-varying characteristics of wave impact loads, these research results are not yet systematic. The research on the wave impact loads of pile caps with complex cross-sectional shapes is insufficient.

\subsection{Current load}

In engineering practice, the current load of the structure is typically calculated via the following formula (Fig. 18):

$$
F_{D}=\frac{1}{2} C_{D} \rho A_{c} v^{2}
$$

where $F_{D}$ is the standard value of the current load; $C_{D}$ is the drag coefficient, which differs among shapes of structures; $\rho$ is the fluid density; $v$ is the design velocity of the current; and $A_{c}$ is the projected area of the component on the plane that is perpendicular to the current direction.

The elevated pile cap foundation is composed of a complex pile group and a cap. The complex arrangement of piles will lead to complexity of the local flow, which renders highly difficult the accurate calculation of the current load of the elevated pile cap foundation using Eq. 9. The research on the current load and drag coefficient of the pile group has always attracted attention. In 2006, Deng (2006) conducted a detailed review of studies on the drag force characteristics of the flow around the pile. The previous results were summarized, and the deficiencies and gaps in the studies were identified. Then, Deng (2007) investigated the drag coefficient values of tandem and parallel double cylinders at various cylinder spacings and proposed a calculation

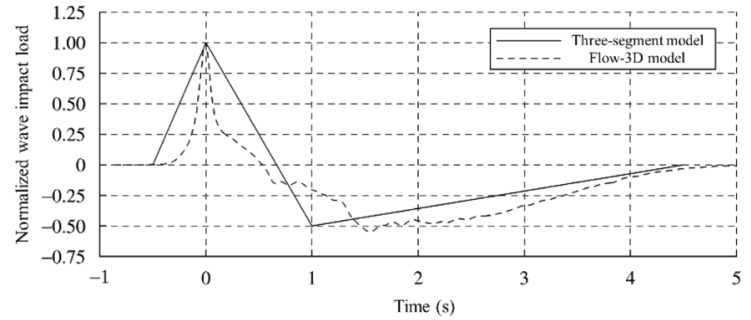

(a)

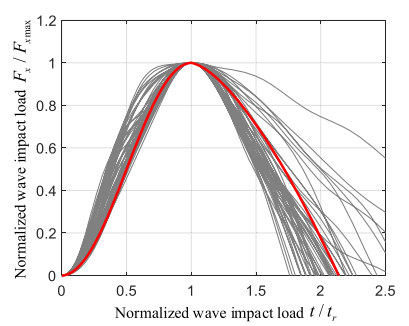

(b)

Fig. 17 Wave impact load time history model 


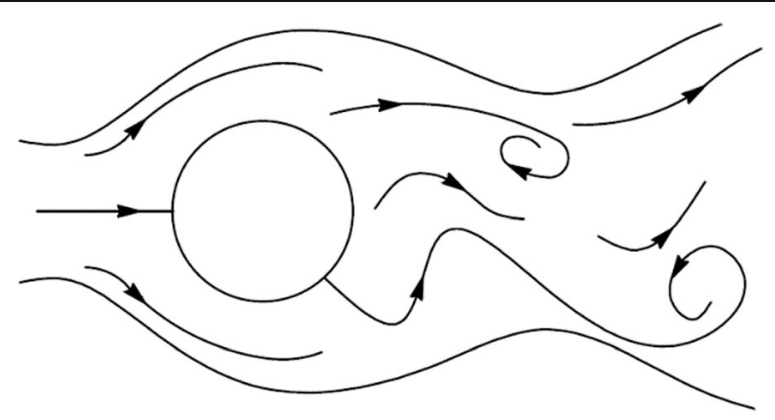

Fig. 18 Interaction between current and structure

formula for the current load of double cylinders. However, according to Lv (2013), the method and formula that were proposed by Deng for calculating the total current load on the pile group have various limitations. Considering tandem and parallel double cylinders as the research object, Deng (2010a) further investigated the shadowing effect and the transverse interference effect of double cylinders experimentally. After summarizing the established research results, Deng (2010b) examined the current load of tandem double cylinders under a uniform current at a limited water depth. The results demonstrated that the shadowing effect coefficient $k_{z}$ of the cylinder is independent of the Reynolds number $R_{e}$ and the current velocity $v$ only if the ratio of the cylinder spacing to the cylinder diameter is $S_{z} / D$. As shown in Fig. 19, the shadowing effect decreases with the increase of $S_{z} / D$. If the ratio of the cylinder spacing to the cylinder diameter is sufficiently large enough, the rear cylinder is no longer affected by the front cylinder.

Based on the finite volume method (FVM), Zhuang et al. (2015) used the tide module TC2D of the COASTALTOOL software to simulate the flow around the pile. In the fine grid model, the influences of the pile section shape, pile group arrangement, and pile spacing on the flow around the pile are examined. In the coarse-grid model, a formula for calculating the drag force of the pile group inside an element based on the principle of drag force superposition was proposed. In addition, a simplification method was proposed for considering the shadowing effect of the pile group in the element.

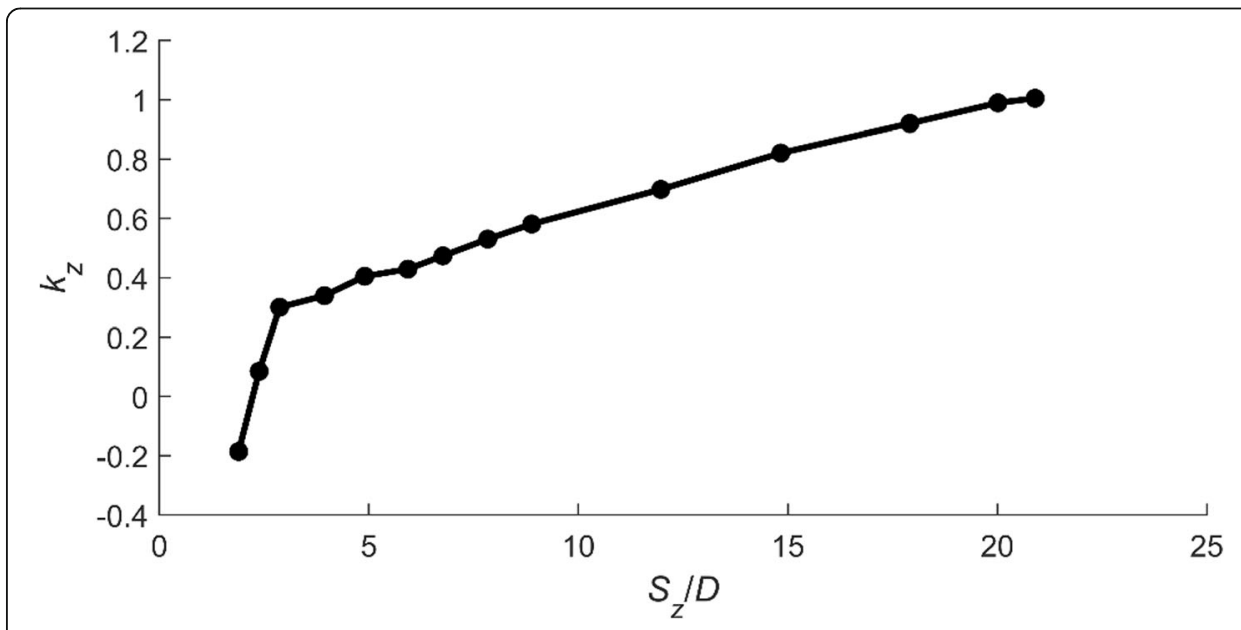

Fig. 19 Relationship between $k_{z}$ and $S_{z} / D$ 
Considering the effects of a two-phase flow, Wu (2019) regarded single-column, double-column, and three-column pile groups with various arrangements and column spacings as the research objects and used numerical simulation software, namely, Fluent, to establish a three-dimensional and two-phase flow model of the flow around columns in the subcritical region. According to the numerical flow field, the current force characteristics of the column, the generation mechanism, and the influence of the column spacing were analysed. In 2020, Yan and Xu (2020) established a threedimensional hydrodynamic numerical model for investigating the distributions of the longitudinal, transverse, and total current forces of a rectangular array pile group under various pile spacings. The longitudinal, transverse, and total current forces of rhomboidal, circular, and dumbbell cylindrical pile groups under various pile spacing were also examined.

Many studies have been conducted on the influences of the cross-sectional shape, pile arrangement, and pile spacing on the current loads on pile groups. However, these studies have not deeply explored the local flow mechanism of complex pile groups.

\subsection{Wave-current load}

\subsubsection{Wave-current load on the pile group}

For the calculation of the wave-current load of a vertical cylinder, an extended form of the Morison equation (Ren 1983) should be utilized, which involves the following two problems: the calculation method for the water particle velocity and the selection coefficients $C_{d}$ and $C_{m}$ (Sarpkaya et al. 1984). The two problems are interrelated and can be examined from the following three perspectives:

\section{1) Universal hydrodynamic coefficients}

According to the experimental results in the wave-current flume, Iwagaki and Li obtained a new $K C^{*}$ number, which correlates with $C_{d}$ and $C_{m}$ in the wave-current field (Iwagaki et al. 1983; Li and Zhang 1986). The $K C^{* \prime}$ number can be expressed as:

$$
K C^{*}= \begin{cases}\frac{u_{m} T}{D}[\sin \theta+(\pi-\theta) \cos \theta] & \left|u_{c}\right|<u_{m} \\ \frac{\pi\left|u_{c}\right| T}{D} & \left|u_{c}\right| \geq u_{m}\end{cases}
$$

where $\theta=\arccos \left(\left|u_{c}\right| / u_{m}\right), u_{m}$ is the peak velocity of the wave particles, and $u_{c}$ is the current velocity.

The $K C^{*}$ number is universally used not only for wave, current, and wave-current fields but also for regular waves and irregular waves (Li et al. 1991).

2) The relationship between $C_{d}$ and $C_{m}$ in the wave-current field and the corresponding coefficients in the wave field

Ren (1985) used the least square method to identify the relationship between $C_{d \text { (wave }}$ - current) and $C_{d \text { (wave) }}$ based on experiments, which is plotted in Fig. 20. Taking $C_{d \text { (wave) }}$ as 1.22, the calculation formula for $C_{d(\text { wave - current) }}$ can be expressed as: 


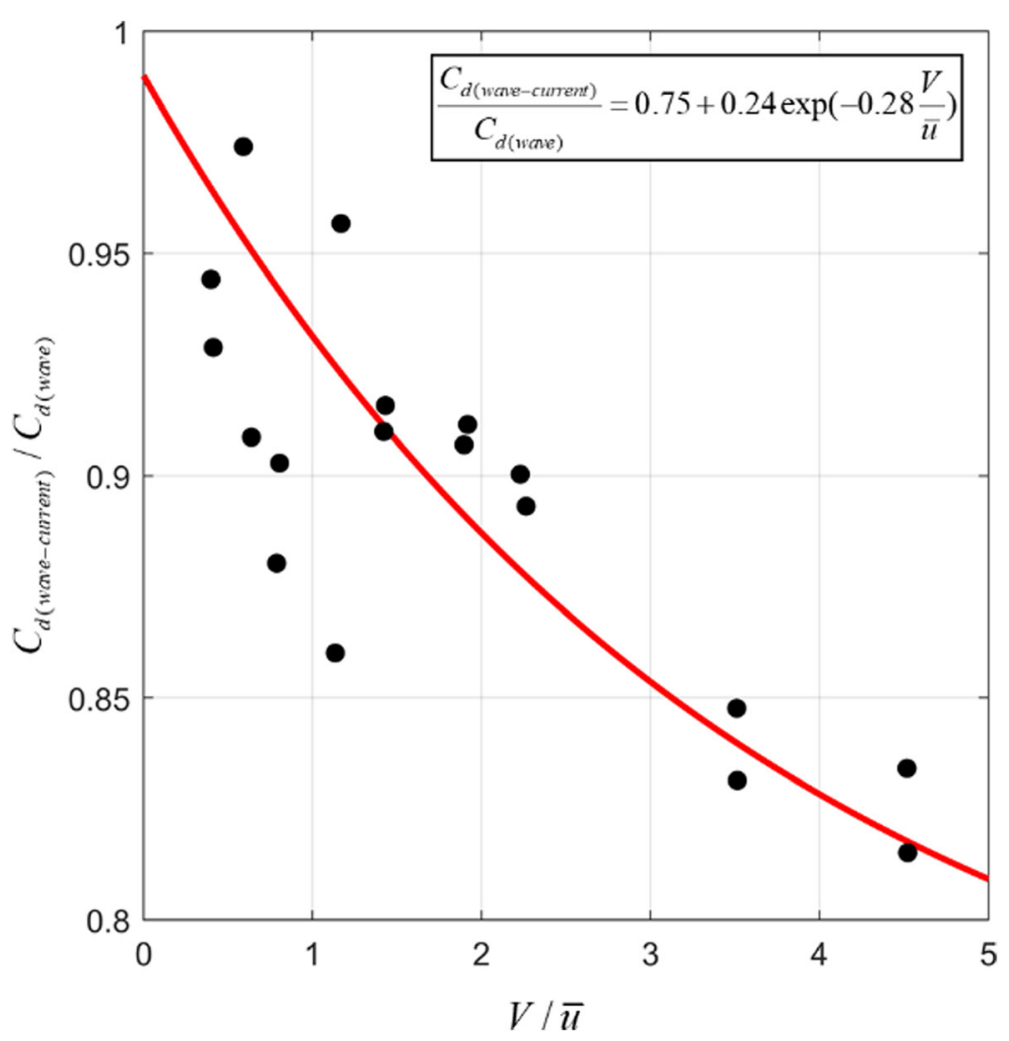

Fig. 20 Relationship between $C_{d(\text { wave-current })}$ and $C_{d(\text { wave })}$

$$
C_{d(\text { wave }- \text { current })}=1.22\left[0.75+0.24 \exp \left(-0.28 \frac{V}{\bar{u}}\right)\right]
$$

where $V$ is the current velocity and $\bar{u}$ is the averaged maximum horizontal velocity of the wave particles along the water depth.

3) The relationship between $C_{d}, C_{m}$ and $K C_{2}=\left(u_{\max }+U\right) T / D$

Wang and $\mathrm{Li}$ (1995) analysed the physical mechanism of wave-current interaction and proposed a method for calculating $C_{d}$ and $C_{m}$ in the wave-current field from the weighted average of $C_{d}$ and $C_{m}$ in the wave field and the current field. Then, the relationship among $C_{d}, C_{m}$ and $K C_{2}=\left(u_{\max }+U\right) T / D$ was identified.

The wave-current load on an inclined pile has yet to be determined. Lan and Huang investigated the wave-current loads of inclined piles and identified a correlation between the wave surface spectrum and the wave-current force spectrum (Lan et al. 2004; Huang et al. 2009).

Similar to waves, when a wave-current interacts with a pile group, the mutual influence among the piles cannot be ignored. Li et al. (1991) regarded tandem and parallel double piles as research objects and explored the variations of the pile group coefficient with the relative pile spacing and the $K C$ number when regular waves and irregular waves interact with currents. Then, Li and Wang (1992a, b) analysed the time-domain and frequency-domain characteristics of the inline, lift, and resultant forces of tandem 
double piles with various pile spacings under the combined action of irregular waves and currents. HuangFu et al. (2004) used experimental methods to investigate the variations of the pile group coefficient with the $K C$ number, current velocity, and water depth when irregular waves interact with currents. Regarding the pile foundation of the Donghai Bridge as the research object, Mei and Liu (2005) analysed the wave-current load of the inclined pile array that is induced by irregular waves and currents. They found that the variation of the pile group coefficient with the $K C$ number is influenced by the current velocity and water depth. Tian (2019a) analysed the variations of wavecurrent loads of a single pile and a pile group with the current velocity. The results demonstrate that when the current velocity is small, the wave-current load of the component pile in the pile group is less than that of the single pile. As the current velocity increases, the wave-current load of the component pile in the pile group becomes larger than that of the single pile.

Under the combined action of waves and currents, the mutual influence among piles is stronger than the effect of the waves, and the research on the pile group coefficient under the wave-current action remains insufficient. Most of the studies focus on simple pile groups, and few studies have been conducted on complex pile groups.

\subsubsection{Wave-current load on the pile cap}

The wave-current loads for large-scale structures must be calculated via various approaches according to the relative strength of the waves and currents ( $\mathrm{Hu}$ et al. 2012). When the wave and current are both weak, their coupling effect can be ignored. The wave load and the current load can be calculated separately via potential flow theory, and the wave-current load can be obtained by linearly superimposing them ( $\mathrm{Hu}$ et al. 2012). In the case of strong waves and weak currents, the weak current assumption and potential flow theory can be used to calculate wave-current loads. Teng (1996) proposed a new integral equation that is suitable for higher-order boundary element methods for solving the problem of the combined action of deep-water waves and weak currents on three-dimensional structures. Under the condition of strong waves and strong currents, potential flow theory is no longer applicable. The studies on the wavecurrent load involve mainly physical model experiments and numerical simulations. Tao and You (1991) conducted a numerical simulation study on the nonlinear interaction between waves and currents and examined the loads that are induced by wavecurrent forces on large-scale structures. $\mathrm{Hu}$ et al. (2012) summarized a calculation method for the wave-current load of a sea-crossing bridge foundation. The problems to be solved were identified, and corresponding solutions were presented. Nie et al. (2013) and Mei et al. (2017) proposed a simplified calculation method for wave-current loads on large-scale rectangular pile caps that was based on a physical model experiment. Liu (2017) used the CFX software to calculate the wave-current loads on the substructure of a sea-crossing bridge and proposed a simplified calculation method. Ji et al. (2019) investigated the hydrodynamic pressure and wave-current force on a steel box cofferdam via field measurement and numerical simulation. Kang et al. (2019) established a numerical model for the interaction between a three-dimensional wave-current field and a large-scale pile cap to analyse the influence of the incident angle on the wavecurrent load. 
Like waves, there will be an impact effect that cannot be ignored when the wavecurrent interacts with the elevated pile cap (Hu et al. 2012). As shown in Fig. 21, when the wave and the current are both strong, the time history curve of the wave-current load has a small peak before the maximum; hence, a substantial impact occurs during the interaction. The impact of the wave-current on elevated pile caps is a challenging topic in the construction of sea-crossing bridges. However, related research is highly scarce. Experimentally, Tian (2019b) investigated the wave-current impact loads on pile caps of various shapes. The influences of the relative wave height and the relative current velocity were analysed. The results demonstrated that the wave-current load on a pile cap increases with the relative wave height, regardless of the shape.

Most scholars use experimental and numerical simulation methods to investigate the wave-current loads on elevated pile caps, and the theoretical research is lacking. No formula has been established for calculating the wave-current impact load on an elevated pile cap.

\section{Fluid-structure interaction}

The size of an elevated pile cap of a sea-crossing bridge is large. When it vibrates, the fluid-structure interaction between the surrounding water and the vibrating pile cap will cause a large additional hydrodynamic force and change the dynamic characteristics of the structure (Jiang et al. 2017, Wei et al. 2019, Zhang et al. 2019). In 2010, Song et al. (2010) regarded the foundation of the South Tower of the Third Nanjing Yangtze River Bridge as the research object and conducted shaking table tests on the foundation using a steel box with and without water. The results of the shaking table tests were compared with those of the simple calculation method of hydrodynamic force under water and no water conditions. It was found that when low-frequency harmonics were input, the results of the simple method were in satisfactory agreement with the test results. When high-frequency harmonics were input, the results of the simple method were 10\% lower than the test results. Huang (2012) also used a steel box that was filled with water to conduct the shaking table test on a pier with a pile group foundation. The method he proposed, which was based on radiation wave theory, for calculating the dynamic interaction between water and the pier under an earthquake action was evaluated. Liu et al. (2012) conducted a shaking table test of a submerged pile-pier system model and discussed the effects of hydrodynamic pressure on the dynamic characteristics and seismic response of the structure. They found that the natural vibration frequency of the model in water is lower than that without water. The magnitude of
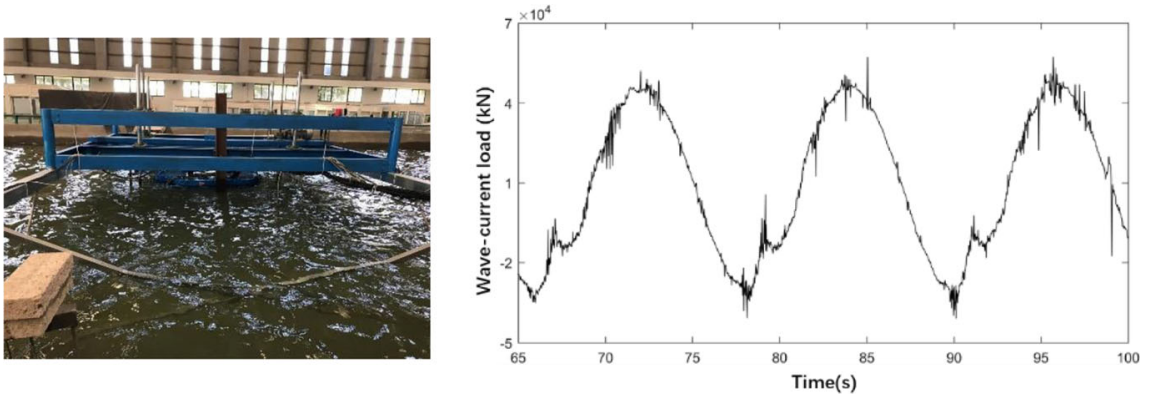

Fig. 21 Wave-current impacts on an elevated pile cap 
the hydrodynamic pressure is related to the peak acceleration and decreases along the height of the model. Wei et al. (2015) used analytical methods to obtain the frequencydomain solution of the dynamic response of deep-water piles in consideration of the combined action of surface waves and earthquakes. The effects of structural flexibility, high-order modal shapes, superstructural contribution, structure-soil interaction, and water compressibility on the dynamic response of the structure are explored.

Hydrodynamic forces can be represented as added masses. Many scholars have developed simplified equations for calculating the hydrodynamic added masses of submerged columns or piers with various cross-sections (Jiang et al. 2017). Lai et al. (2004) proposed a semi-analytical and semi-numerical method for calculating the hydrodynamic pressure on cylindrical piers under an earthquake. Based on the Morrison equation, Gao and Zhu (2006) used an added mass to consider the effect of water and proposed the use of the relative water depth in seismic design to determine whether it is necessary to consider the hydrodynamic pressure. Wang et al. (2011) idealized an elevated pile cap as a truncated cylinder that was immersed in water and established a calculation method for the added mass matrix and added damping matrix of the pile cap. An approximate method for equating a non-cylindrical pile cap to a cylindrical pile cap was proposed. The seismic motion equation of a deep-water elevated pile cap foundation was established in the frequency domain. This study only considered the pile cap and not the dynamic response of the pile group foundation. As shown in Fig. 22, Wei et al. (2013) conducted an experiment and used a three-dimensional finite element model to investigate the fluid-structure interactions of a deep-water pile group during free vibration. The influences of water depth changes, the pile cap shape, and the pile foundation arrangement on the dynamic characteristics and hydrodynamic pressure distribution of deep-water pile foundations were explored. Pang et al. (2015) developed a numerical program for calculating the added mass of rectangular pile caps that were immersed in water by using the ratio of natural frequencies with and without the effect of fluid-structure interaction. Regarding rectangular pile caps as the research objects, Zhang et al. (2020) used Latin hypercube sampling (LHS) to sample pile caps with various physical parameters. The added mass coefficients of all pile cap samples were calculated via a three-dimensional potential-based numerical method. A Bayesian updated analytical model of the hydrodynamic added mass of a rectangular pile cap was proposed.

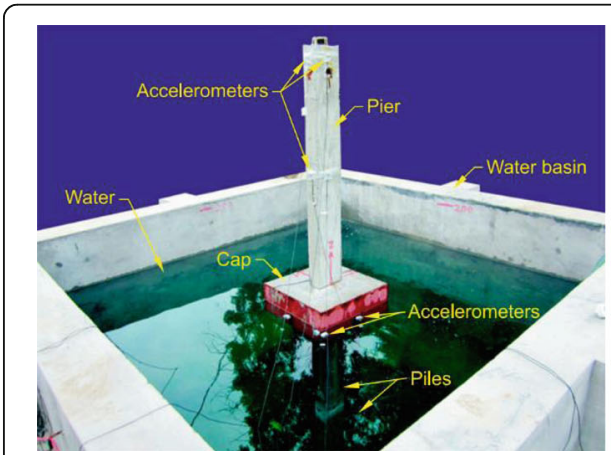

(a) Shaking table test photographs

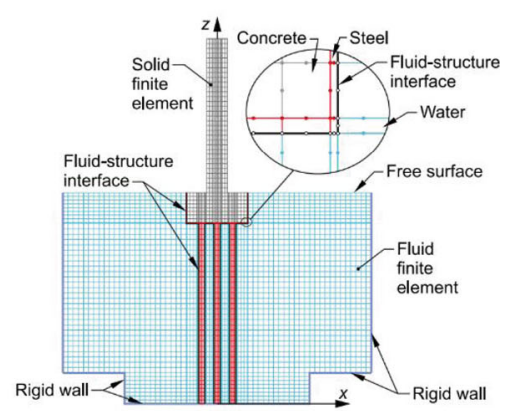

(b) Three-dimensional finite element model

Fig. 22 Fluid-structure interaction of a deep-water pile group during free vibration 
Although fluid-structure interaction analysis is an effective method for solving for the seismic response of elevated pile cap foundations of sea-crossing bridges, many aspects of this method must be improved, such as the selection of control equations, the control of grid movement, the determination of initial conditions of ground motions, and the selection of fluid-structure interaction algorithms.

\section{Structural responses of bridges that are supported by elevated pile cap foundations}

The elevated pile cap of a sea-crossing bridge has large upper weight and small lateral stiffness; hence, it is sensitive to impact loads. When the pile cap is subjected to an impact load, a highly complicated dynamic response will be induced (Guo et al. 2011). Researchers have often used static methods to determine the bearing capacities of offshore structures (Golafshani et al. 2011; Wei et al. 2014). However, the marine environment is constantly changing with time and space. Although the static analysis method is simple and fast, it cannot evaluate the real dynamic responses of these structures (Golafshani et al. 2011). Golafshani et al. (2011) compared the static and dynamic incremental wave analysis (SIWA and DIWA) results of the SPD2 and DS jacket platforms under wave action. As shown in Fig. 23, the SIWA method will underestimate the structural response under wave action and increase the risk of structural damage.

\subsection{Wave and current responses}

Waves and currents often impact the elevated pile cap foundations of sea-crossing bridges. It is necessary to investigate the dynamic response of such a structure under waves and currents. Hallam et al. (1977) used the finite element method to discretize the structure. The wave load was calculated via an analytical method, and the dynamic equation under wave action was established. This method was used to examine the dynamic response of a fixed structure under the action of waves and currents. Laya et al. (1984) improved the above method by using the relative velocity of the wave and the structure to consider the effect of wave-structure interaction on the dynamic response of the structure. Guo et al. (2011) conducted an experimental study on the dynamic responses of marine structures under wave impact loads. The maximum acceleration response of the platform structure under wave impact load and its possible occurrence
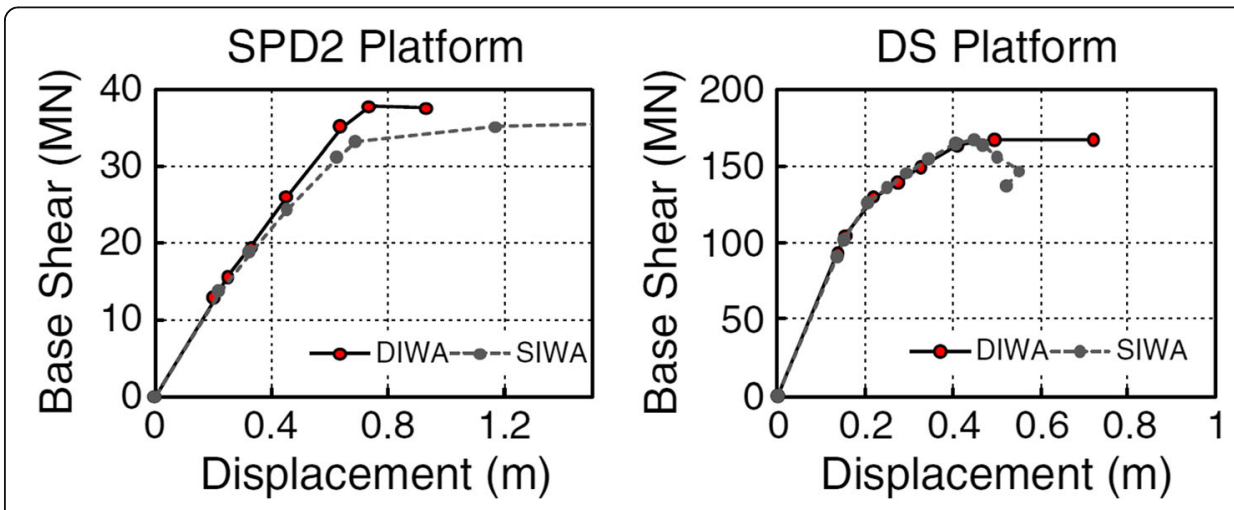

Fig. 23 Comparison between DIWA and SIWA 
times were obtained. Zhang (2012) used the ABAQUS and FLUENT software to conduct fine finite element discretization of structures and fluids, respectively, and used the MPCCI software to solve the fluid-structure interaction vibration equation of double-column piers under wave-current action. Regarding the buried pile cap of the Hong Kong-Zhuhai-Macao Bridge as the research object, Wu et al. (2014) analysed the dynamic response of the pile foundation under wave-current action. Wang and Chen (2014) used the improved JONSWAP spectrum to simulate irregular waves and used the Morison equation to calculate the wave load on a steel pipe pile. The finite element method and the Newmark method were used to solve for the dynamic response of a trestle steel pipe pile under wave-current loads. Pan et al. (2020) used Abaqus to establish a three-dimensional finite element model of a single pile and pile groups under the conditions of multi-layer soil and single-layer soil. The Morison equation was used to calculate the wave-current load, and the responses of each model under various load conditions were determined.

In a numerical simulation study of the dynamic response of the elevated pile cap foundation under a wave-current action, a fully coupled simulation of the fluidstructure interaction is difficult to realize. The wave-current force is applied to the structure as an external load. Studies on the fluid-structure interactions of elevated pile cap foundations and wave-currents still rely mainly on physical experiments.

\subsection{Multi-hazard response}

In contrast to land bridges, sea-crossing bridges are in a complex and variable marine environment. When an earthquake occurs, a sea-crossing bridge will bear the combined action of the seismic excitation and hydrodynamic pressure that are generated by waves and currents. A seismic analysis of sea-crossing bridges must consider the combined action of waves and currents. Li and Huang (2012) used diffraction theory to consider the effect of waves and used radiation theory to consider the hydrodynamic pressure. Using a self-compiling program, they analysed the dynamic response of a bridge pier under the combined action of an earthquake and waves. Yuan and Liu (2013) conducted dynamic calculations on the piers of Zhanjiang East Island Bridge. They determined that when waves and earthquakes act simultaneously, the horizontal force and bending moment of the pile substantially exceed those when the earthquake is acting alone. Lin and Yuan (2015) established a method for analysing the seismic responses of deep-water bridge piers under wave action. The dynamic responses of a bridge pier under three working conditions were analysed: earthquake action only, wave action only, and earthquake and wave action simultaneously.

Waves and currents in the ocean often occur at the same time, and the dynamic responses of sea-crossing bridges under the combined action of earthquakes and wavecurrents cannot be ignored. Chen et al. (2008) used the fifth-order Stokes wave theory and the Morison equation to calculate wave forces and applied the calculated wave forces on the piers in the form of distributed forces. Then, the nonlinear seismic response characteristics of deep-water bridge piers under the action of wave-currents were analysed. Regarding the deep-water foundation of the Qiongzhou Strait Bridge as the research object, Chen et al. (2015) used finite element dynamic analysis methods to investigate the effects of various hazards such as earthquakes, ship collisions, and 
waves. The displacement response of a deep-water foundation was analysed, and its dynamic response characteristics were discussed. Liu and Zhang (2017) systematically reviewed the research progress on sea-crossing bridges under the individual or combined action of waves, currents, and earthquakes and discussed future prospects. Based on the nonlinear Morison equation, Wu et al. (2018) established the structural dynamics equation under the combined action of waves, currents, and earthquakes. Through finite element discretization, the dynamic response of a deep-water pile-cap-pier structure system was calculated, and the influences of various wave and current parameters were analysed. Wu et al. (2018) used a numerical simulation method to calculate the displacement and stress response of a pile foundation under the action of wavecurrents and earthquakes. The influences of the relative water depth, relative velocity ratio, wave steepness, period, direction angle, and phase angle were analysed. Using ADINA, Jiang et al. (2019) established a fluid-structure interaction model for investigating the combined action of waves, currents, and earthquakes on deep-water piers and discussed the influences of various wave and current parameters on the dynamic responses of deep-water piers. Yun and Liu (2020) regarded a deep-water high-pier whole bridge as the research object. Under the combined action of waves, currents, and earthquakes, they conducted a shaking table test on a 1:220 geometric scale model (Fig. 24a). As shown in Fig. 24b, acceleration sensors, strain sensors, and hydrodynamic pressure sensors were installed on the model to record the structural response and the hydrodynamic pressure. According to the experimental results, the combined effects of earthquakes, waves, and currents are not simply superimposed effects. There are complex interactions among them.

Limited by the conditions of the underwater shaking table test, the study on the dynamic response of an elevated pile cap foundation under the combined action of waves, currents, and earthquakes uses mostly numerical simulation methods, which lack the support of reliable experimental data.

\section{Conclusions and prospects}

In the design and construction of elevated pile caps of sea-crossing bridges, the influence of hydrodynamic effects such as waves, tidal currents, and earthquakes must be considered. The experimental and theoretical studies on these loads have continuously

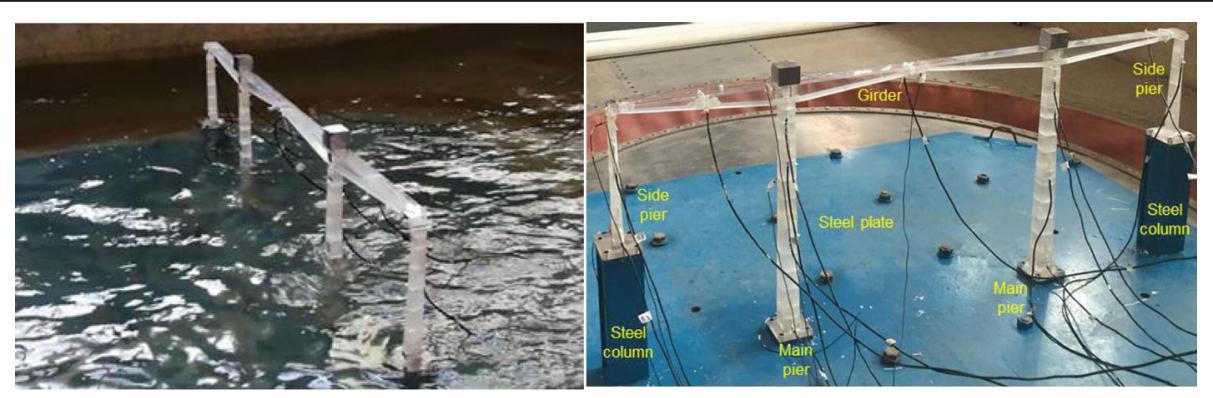

(a) Test photograph

(b) Sensor layout

Fig. 24 Shaking table test of a deep-water high-pier whole bridge model under the combined action of waves, currents, and an earthquake 
deepened, and the results have been referenced and applied in bridge designs. In this paper, the literature visualization analysis method is used to analyse the research results on the hydrodynamic effects of elevated pile cap foundations that have been obtained over the past 20 years. The development route and knowledge structure of the research are summarized. By reviewing the studies that have been conducted on the hydrodynamic effects of elevated pile cap foundations, the following unresolved problems are identified:

(1) Physical model tests and numerical simulations are the main methods for investigating the interaction between a wave-current and an elevated pile cap foundation. However, they all have limitations in simulating wave-current interactions. The test conditions limit the applicability of the physical model test, and it is difficult to simulate a high-Reynolds-number environment. Numerical methods for simulating the interactions between irregular waves and currents have not been reported. The wave-current interactions mechanism requires in-depth investigation.

(2) The hydrodynamic loads on single piles and pile groups have been examined by many scholars. Some of these loads can be calculated by following the corresponding design standards. However, the complex local flow that is caused by the hydrodynamic effects on the pile group foundation requires in-depth investigation.

(3) With the increase of the wave height and the current velocity, the interaction of an elevated pile cap with waves and currents will gradually show a substantial impact effect, which involves complex factors such as wave breaking and strong nonlinearity. The mechanism of wave and current impact has yet to be elucidated, and no calculation method for the wave-current impact load has been reported.

(4) Fluid-structure interaction analysis is an effective method for determining the seismic responses of elevated pile cap foundations of sea-crossing bridges. However, fully coupled fluid-structure interactions under the combined action of waves, currents, and earthquakes is difficult to realize.

(5) Research on the structural dynamic response under hydrodynamic with other hazards requires dynamic tests under multiple excitations of earthquakes, waves, and currents. Such tests can provide reliable data and information support for the theoretical investigation of the dynamic responses of elevated pile foundations under the combined action of earthquakes, waves, and currents.

Therefore, the combined application of the physical model test, numerical simulation method, and theoretical analysis is of substantial significance and value for research on the hydrodynamic effects on elevated pile cap foundations of sea-crossing bridges.

\footnotetext{
Abbreviations

$H$ : Wave height; $T$ : Wave period; $g$ : Acceleration of gravity; L: Wavelength; $f_{H}$ : The wave load per unit length of a vertical cylinder at any height; $f_{D}$ : The drag force; $f_{M}$ : The inertial force; $u$ : The velocity of the water particle; $\frac{d u}{d t}$ : The acceleration of the water particle; $C_{d}$ : The drag force coefficient; $C_{m}$ : The inertial force coefficient; $\rho$ : Fluid density; KC: Keulegan-Carpenter number; $R_{e}$ : Reynolds number; CFD: Computational fluid dynamics; FVM: Finite volume method; LHS: Latin hypercube sampling; SIWA: Static incremental wave analysis; DIWA: Dynamic incremental wave analysis
} 


\section{Authors' contributions}

Conceptualization, K. W.; Formal analysis, M. Z., Z. T.; Investigation, C. Z., M. Z., Z. T.; Supervision, K. W., M. Z. and S. Q.; Writing-original draft, K. W., C. Z.; Writing - review \& editing, K. W., and Z. C. All authors have read and agreed to the published version of the manuscript.

\section{Funding}

This work was supported financially by the National Natural Science Foundation of China (Grant Nos. 51978578 and 51708455) and the Fundamental Research Fund for Central Universities (A1920502051907-2-001).

\section{Availability of data and materials}

All data, models, and code used during the study appear in the published article.

\section{Competing interests}

The author(s) declared no potential conflicts of interest with respect to the research, authorship, and/or publication of this article.

\section{Author details}

${ }^{1}$ Department of Bridge Engineering, Southwest Jiaotong University, Chengdu 610031, China. ${ }^{2}$ China Railway Major Bridge Reconnaissance \& Design Institute Co., Ltd., Wuhan 430050, China.

Received: 26 November 2020 Accepted: 8 December 2020

Published online: 31 December 2020

\section{References}

Andrzej S, Ryszard S (2008) Wave-induced stresses and pore pressures near a mudline. Oceanologia 50(4):539-555 Brevik I, Bjørn A (1979) Flume experiment on waves and currents. I. Rippled bed. Coast Eng 3:149-177

Brevik I, Luftkrigsskolen, Trondheim (1980) Flume experiment on waves and currents II. Smooth bed. Coast Eng 4:89-110

Chen B (2016) Characteristics of offshore ground motions and seismic response analysis of sea-crossing bridges. Dalian University of Technology, Dalian

Chen C (2006) CiteSpace II: detecting and visualizing emerging trends and transient patterns in scientific literature. J Am Soc Inf Sci Technol 57(3):359-377

Chen F, Che A, Fu B, Liu G (2015) Dynamic stability of deep water foundation of extra-large bridge under multiple disasters. J Shanghai Jiao Tong Univ 49(7):993-997+1004

Chen G, Bai D, Wang Z (2008) Seismic response analysis of large scale bridge pier supported by pile foundation considering the effect of wave and current action. J Earthq Eng Eng Vib 28(5):170-177

Chen Q (1981) Waves of the Taiwan Strait. Mar Sci Bull 10(3):1-11

Chen Q, Wang L, Zhao H (2009) Hydrodynamic investigation of coastal bridge collapse during hurricane Katrina. J Hydraul Eng 135(3):175-186

Chen S (2019) Study of scouring protection schemes for pier foundation of DongHai bridge. World Bridges 47(4):17-21

Chen X, Mei X (2016) Design of deepwater foundations of main ship channel cable-stayed bridge of Pingtan Straits rail-cumroad bridge. Bridge Constr 46(3):86-91

Cheng C, Zhang Y, Chen H (2008) Design of steel pipe pile foundation for Hangzhou bay cross-sea bridge project. Port Waterw Eng 33(10):150-156

Cui M, Wen W, Yan A, Wang P, Li G (2019) General design of deep water foundation of Jintang double suspension highwayrailway sea-crossing bridge. In: Proceedings of the 9 th technical forum on bridge and tunnel engineering, vol 9

Dean RG, Dalrymple RA (1991) Water wave mechanics for engineers and scientists. World Scientific Publishing, Singapore

Deng S (2006) Current situation and prospect of study on drag force characteristics of piles. Port Waterw Eng 31(09):10-15

Deng S (2007) Drag force characteristics and calculation of water flow around pile. China Harbour Eng 27(1):4-6

Deng S (2010a) Research on the influence characteristics of cylindrical flow resistance in uniform flow with finite depth. Yellow River 32(5):36-37+40

Deng S (2010b) Research on the shadowing effect of the cylinder in uniform current with limited water depth. Yellow River 32(5):36-37+40

Ding Y, Ma R, Li N (2015) A simulation model for three-dimensional coupled wave-current flumes. Eng Mech 32(10): $68-74+88$

Ding Z, Ren B, Wang Y, Ren X (2008) Experimental research on random wave impact on three-dimensional structure in splash zone. J Dalian Univ Technol 48(6):904-911

Dong L, Zhu Y, Hu J, Shao J (2020) Numerical simulation study of wave load on large-size cap of cross-sea bridge. J Waterw Harb 41(1):50-57

Fang Q (2012) Study on extreme wave loads of coastal highway bridges. Harbin Institute of Technology, Harbin

Gao X, Zhu X (2006) Hydrodynamic effect on seismic response of bridge pier in deep water. J Beijing Jiaotong Univ 30(1):55-58

Golafshani AA, Bagheri V, Ebrahimian H, Holmas T (2011) Incremental wave analysis and its application to performance-based assessment of jacket platforms. J Constr Steel Res 67(10):1649-1657

Guo A, Hui F, Qing H, Bai X (2015) Hydrodynamic experiment of the wave force acting on the superstructures of coastal bridges. J Bridg Eng 20(12):04015012

Guo B, Ren B, Liu M (2011) Dynamic responses of marine structures due to wave impact. J Waterw Harb 32(3):168-172

Hallam MG et al (1977) Dynamics of marine structures: methods of calculating the dynamic response of fixed structures subject to wave and current action. Ciria Underwater Engineering Group, London

Hu Y, Lei L, Yang X (2012) Study of wave force on foundation of sea-crossing bridges. J Waterw Harb 33(2):101-105

Huang H, Zhang D, Xu L, Yang C (2002) The state-of-art of deep foundation in bridge engineering. J Highway Transp Res Dev 19(4):60-64 
Huang S, Liu H, Liu S (2009) Research on single pile model hydrodynamic experiment of sea-crossing bridge foundation. Struct Eng 25(6):111-116

Huang W, Xiao H (2009) Numerical modeling of dynamic wave force acting on Escambia Bay bridge deck during hurricane Ivan. J Waterw Port Coastal Ocean Eng 135(4):164-175

Huang X (2012) Mechanism of water - bridge pier dynamic interaction and nonlinear seismic responses of bridges in deep water. Tianjin University, Tianjin

HuangFu X, Lan Y, Xue L, Chen G, Liu H (2004) Experimental investigation of irregular wave and current loads on group piles. World Bridges (S1):32-36

Iwagaki Y, Asano T, Nagai F (1983) Hydrodynamic forces on a circular cylinder placed in wave-current co-existing fields. Mem Fac Eng Kyoto Univ 45(1):11-23

Ji Z, Fan L, Zhao D, Zhu B, Kang A, Li Z (2019) Study on computational method of wave-current force on large-scale rectangular steel boxed cofferdam. Railway Constr Technol 36(3):1-6

Jiang H, Bai X, Huang L, Li C, Meng X, Yang Q (2019) Seismic response characteristics of deep-water piers of sea-crossing bridges wave-current environment. J China Railway Soc 41(3):117-127

Jiang H, Wang B, Bai X, Zeng C, Zhang H (2017) Simplified expression of hydrodynamic pressure on deepwater cylindrical bridge piers during earthquakes. J Bridge Eng 22(6):04017014

Kang A, Zhang J, Zhu B, Yin R, Xu J (2019) Numerical simulation of interaction of oblique waves and currents and large-scale rectangular pile cap. World Bridges 47(1):65-70

Kemp PH, Simons RR (1982) The interaction between waves and a turbulent current: waves propagating with the current. J Fluid Mech 116:227-250

Kemp PH, Simons RR (1983) The interaction of waves and a turbulent current: waves propagating against the current. J Fluid Mech 130(1):73-89

Korteweg DJ, de Vries G (1895) On the change of form of long waves advancing in a rectangular canal, and on a new type of long stationary waves. Lond Edinb Dubl Phil Mag J Sci 39(240):422-443

Kriebel DL (1998) Nonlinear wave interaction with a vertical circular cylinder: wave forces. Ocean Eng 25(7):597-605

Lai W, Wang J, Hu S (2004) Earthquake induced hydrodynamic pressure on bridge pier. J Tongji Univ 32(1):1-5

Lan Y, Guo W, Liu H, Song Q, Yuan J (2010) Experimental study on hydrodynamic loads on a horizontal slab and pile in regular wave. Chin J Hydrodynam 25(4):551-558

Lan Y, Xue L, Liu H, Huan F, Chen G, Yang J (2004) Experimental studies on hydrodynamic loads on piles and slab of Donghai bridge part I: hydrodynamic forces on a single pile in wave-current combinations. J Hydraul 19(6):753-758

Larmaei MM, Mahdi TF (2010) Simulation of shallow water waves using VOF method. J Hydro Environ Res 3(4):208-214

Laya EJ, Connor JJ, Sunder SS (1984) Hydrodynamic forces on flexible offshore structures. J Eng Mech 110(3):433-448

Lei X (2013) Research on hydrodynamic performance of pile array under wave action. Dalian University of Technology, Dalian

Lewis JK (1997) A three-dimensional ocean circulation model with wave effects. In: Estuarine \& coastal modeling, pp 584-600

Li J, Ji X, Zhang H (2017) Comparison of wave force calculation methods for large-scale cap structures. Highway 62(8):362-365

Li J, Li Z, Xue L (2019) Study on unified empirical formulas of wave forces for geometrically asymmetrical pile-supported structures. Chin J Hydrodynam 34(4):475-481

Li Y (1982) Effect of wave-current interaction on the wave parameter. J Dalian Univ Technol 21(04):81-91

Li Y (1983) Velocity field for interacting waves and currents. Ocean Eng 04:12-23

Li Y, Lin M (2010) Hydrodynamic coefficients induced by waves and currents for submerged circular cylinder. Procedia Eng 4: 253-261

Li Y, Wang F (1992a) Wave-current force acting on parallel double piles. Acta Oceanol Sin 14(2):106-121

Li Y, Wang F (1992b) Waves-current forces acting on the series of double piles. Chin J Hydrodynam 7(2):141-149

Li Y, Wang F, Kang H (1991) Wave-current forces on slender circular cylinders. China Ocean Eng 11(03):287-310

Li Y, Zhang F (1986) Waves and currents acting on vertical piles. Acta Oceanol Sin 8(6):751-761

Li Z, Huang X (2012) Dynamic responses of bridges in deep water under combined earthquake and wave actions. China Civil Eng J 45(11):134-140

Li Z, Ni X, Xue L (2020) Experimental study of the wave force on the geometrically asymmetrical pile-supported structures and pile group effect coefficient. Chin Q Mech 41(3):508-518

Lin C, Yuan W (2015) Seismic response of bridge pier in deep water considering wave action. J Civ Eng Manag 32(2):37-41

Liu C, Sun G, Han L (2012) A vibration test on a submerged pile-pier system model. J Earthq Eng Eng Vib 32(5):97-102

Liu C, Zhang S (2017) Research progress of sea-crossing bridge structure considering action of earthquake, wave and current. J Dalian Univ Technol 57(1):105-110

Liu G, Wang Q, Tian X, Xie Y (2020) Recent research and progress on hydrodynamic coefficients of marine structures with small scale pile. Periodical Ocean Univ China 50(1):136-144

Liu $L$ (2017) Research on computing method of wave-current force on sea-crossing bridge substructures. Southwest Jiaotong University, Chengdu

Longuet-Higgins MS, Stewart RW (1961) The changes in amplitude of short gravity waves on steady non-uniform currents. J Fluid Mech 10(04):529-549

Lv Q (2013) Research on the water force numerical calculation of large water level difference in the mountainous area, river to the structure of frame pier wharf. Chongqing Jiaotong University, Chongqing

Ma R, Zhao X (2002) Spectral study on wave loadings of random waves with the third stokes type. Mar Sci 26(11):38-43

Méhauté B (2013) An introduction to hydrodynamics and water waves. Springer Science \& Business Media, Germany

Mei D, Liu Q, Hu Y, Wang D (2017) Study of calculation methods and composite coefficient of wave-current forces for seacrossing bridge pile caps and implementation. World Bridges 45(1):51-55

Mei Y, Liu H (2005) Experimental studies on hydrodynamic loads on piles and slab of Donghai bridge-part II: hydrodynamic forces on pile array and slab in wave-current combinations. Chin J Hydrodynam 20(3):332-339

Murphy RR, Steimle E, Hall M, Lindemuth M, Trejo D, Hurlebaus S, Medina-Cetina Z, Slocum D (2009) Robot-assisted bridge inspection after hurricane Ike. In: 2009 IEEE international workshop on safety, security rescue robotics (SSRR 2009), pp 1-5

Nie F, Pan J, Wang X, Wang X (2013) A study of wave-current force acting on large scale cylinder structures. Hydro-Sci Eng 38(03):65-70 
Padgett JE, Spiller A, Arnold C (2012) Statistical analysis of coastal bridge vulnerability based on empirical evidence from hurricane Katrina. Struct Infrastruct Eng 8(6):595-605

Palma PD, Tullio D, Pascazio G, Napolitano M (2006) An immersed-boundary method for compressible viscous flows. Comput Fluids 35(7):693-702

Pan L, Zhu B, Zhang J, Kang A (2020) Dynamic response analysis of pile foundation of cross sea bridge under wave-current load considering multiple soil layers. Railway Stand Des 64(12):1-8

Pang Y, Kai W, Yuan W, Shen G (2015) Effects of dynamic fluid-structure interaction on seismic response of multi-span deep water bridges using fragility function method. Adv Struct Eng 18(4):525-541

Park JC, Kim MH, Miyata H (2001) Three-dimensional numerical wave tank simulations on fully nonlinear wave-current-body interactions. J Mar Sci Technol 6(2):70-82

Qin N, Lu C, Li J (2013) Research on the method of constructing a numerical wave -current flume. Chin J Hydrodynam 28(3): 349-356

Qiu Z, Wu Q, Niu Z (2013) Experimental study on scouring and siltation in foundation excavation for embedded capping blocks for Hong Kong-Zhuhai-Macao bridge. China Harbour Eng 33(01):25-28

Qiu Z, Zhao D (2019) Study on numerical simulation of wave load on main bridge foundation cap for China and Maldives friendship bridge. Constr Technol 48(5):5-8

Raaij KV, Gudmestad OT (2007) Wave-in-deck loading on fixed steel jacket decks. Mar Struct 20(3):164-184

Ren B, Li X, Wang Y (2006) Experimental investigation of instantaneous properties of the flow field of wave slamming. Ocean Eng 24(4):68-74

Ren B, Wang Y (1999) Nonlinear wave impact on structures. J Dalian Univ Technol 39(4):562-566

Ren B, Wang Y (2003) Time-domain analysis of irregular wave slamming on subface of open-piled structures. J Dalian Univ Technol 43(6):818-824

Ren Z (1983) Calculation of the combined force of waves and currents on isolated piles. Acta Oceanol Sin 5(3):376-390

Ren Z (1985) Research on the force coefficient on isolated piles in wave-current field. Acta Oceanol Sin 7(4):503-512

Sarpkaya T, Bakmis C, Storm MA (1984) Hydrodynamic forces from combined wave and current flow on smooth and rough circular cylinders at high Reynolds numbers. In: Offshore technology conference. Offshore Technology Conference, Houston

Sarpkaya T, Isaacson M, Wehausen JV (1982) The mechanics of ware forces on offshore structures. J Appl Mech 49(2):466-467

Song B, Zhang G, Li Y (2010) Shaking table test of pier water interaction. J Univ Sci Technol Beijing 32(3):403-408

Stokes GG (1847) On the theory of oscillatory waves. Trans Cambridge Philos Soc 8:441-455

Suchithra N, Koola PM (1995) A study of wave impact of horizontal slabs. Ocean Eng 22(7):687-697

Tao J, You X (1991) The numerical simulations of wave-current fields and wave-current loads on a large cylinder. Acta Aerodynamica Sin 9(1):80-87

Teng B (1996) The effect of waves and weak currents on structures in deep water. Acta Oceanol Sin 18(5):117-127

Thomas GP (1981) Wave-current interactions: an experimental and numerical study. Part 1. Linear waves. J Fluid Mech 110: $457-474$

Thomas GP (1990) Wave-current interactions: an experimental and numerical study. Part 2. Nonlinear waves. J Fluid Mech 216:505-536

Ti Z, Zhang M, Li Y, Wei K (2019) Numerical study on the stochastic response of a long-span sea-crossing bridge subjected to extreme nonlinear wave loads. Eng Struct 196:109287

Tian H (2019a) Research on the force of pile group under the combined action of linear wave and current. SiChuan Arch 39(04):108-110

Tian H (2019b) Study on the wave-current combined force characteristics of group piles-cap structure. Southwest Jiaotong University, Chengdu

Tian J (2010) Underwater foundation construction technology of elevated deep-water pile in bay bridge of Qingdao. Shanxi Arch 36(9):311-312

Veritas DN (2010) Recommended practice DNV-RP-C205: environmental conditions and environmental loads. DNV, Norway

Wang C, Chen B (2014) Numerical simulation of dynamic response of steel pipe piles under wave-current action. China Water Transp 14(4):102-105

Wang J, Lai W, Hu S (2011) Seismic hydrodynamic effects on group-pile foundations with caps merged in water. J Tongji Univ Nat Sci 39(5):650-655

Wang S, Liang B (1991) Wave mechanics for ocean engineering. China Ocean University Press, Qingdao

Wang T, Li J (1995) Effect of wave-current interaction on hydrodynamic coefficients. Chin J Hydrodynam 10(5):551-559

Wang T, Li J (1996) Application of conservation law of wave action flux to wave-current interaction. Theor Appl Mech 28(3):26-35

Wang T, Li J (1999) On wave-current interaction. Adv Mech 29(3):331-343

Wei C (2012) Numerical simulation of combined actions of wind, wave and current and their actions on cylindrical component. Harbin Institute of Technology, Harbin

Wei K, Arwade SR, Myers AT (2014) Incremental wind-wave analysis of the structural capacity of offshore wind turbine support structures under extreme loading. Eng Struct 79(nov.15):58-69

Wei K, Bouaanani N, Yuan W (2015) Simplified methods for efficient seismic design and analysis of water-surrounded composite axisymmetric structures. Ocean Eng 104(aug.1):617-638

Wei K, Yuan W, Bouaanani N (2013) Experimental and numerical assessment of the three-dimensional modal dynamic response of bridge pile foundations submerged in water. J Bridg Eng 18(10):1032-1041

Wei K, Zhang J, Qin S (2019) Experimental and numerical assessment into frequency domain dynamic response of deep water rigid-frame bridge. J Earthq Eng :1-24

Wei K, Zhou C, Xu B (2020) Probability model of wave impact load on the elevated pile cap for sea-crossing bridges. Eng Mech 37(6):216-224

Wienke J, Oumeraci H (2005) Breaking wave impact force on a vertical and inclined slender pile-theoretical and large-scale model investigations. Coast Eng 52(5):435-462

Wu A, Yang W, Zhao L (2018) Influence of wave-current interaction on seismic response of deep-water bridge. World Bridges 46(4):73-77 
Wu C (2019) Analysis of force and flow characteristics of flow around columns of bridge. Southwest Jiaotong University, Chengdu

Wu Q, Niu Z, Tian W, Zhu H (2014) Dynamic response analysis and experimental research on the interaction between wavecurrent and buried pile cap of Hong Kong-Zhuhai-Macao bridge. J China Foreign Highway 34(1):121-124

Xiao H, Huang W, Tao J, Liu C (2013) Numerical modeling of wave-current forces acting on horizontal cylinder of marine structures by VOF method. Ocean Eng 67:58-67

Xu B, Wei K (2019) Numerical simulation of wave forces on elevated pile cap of sea-crossing bridges based on RANS. Railway Stand Des 63(12):79-84

Xu G, Cai CS (2015) Wave forces on Biloxi Bay bridge decks with inclinations under solitary waves. J Perform Constr Facil 29(6):04014150

Yan J, Xu H (2020) 3D numerical simulation study on flow force characteristics of complex grouped piles. Port Eng Technol $57(2): 1-5$

Yao W, Liu H (2009) Effect of circular slab for wave loads on piles in regular waves. Chin Q Mech 30(3):357-362

Yuan W, Liu M (2013) Load effect analysis of crossing-sea bridge's pier on the wave and earthquake effect. J Wuhan Univ Technol 35(12):120-124

Yun G, Liu C (2020) Shaking table tests on a deep-water high-pier whole bridge under joint earthquake, wave and current action. Appl Ocean Res 103:102329

Zhang H, Liu S, Li J, Zhang R (2018) Experimental study on piles grouping effect of side by side 9 piles under the action of multi-directional irregular waves. Ocean Eng 36(6):17-26

Zhang J, Wei K, Pang Y, Zhang M, Qin S (2019a) Numerical investigation into hydrodynamic effects on the seismic response of complex hollow bridge pier submerged in reservoir: case study. J Bridge Eng 24(2):05018016

Zhang J, Wei K, Qin S (2020) Bayesian updating model for structural vibration-induced hydrodynamic added mass of rectangular pile cap submerged in water. J Eng Mech 146(9):04020096

Zhang J, Zhang Y, Jeng D, Liu P, Zhang C (2014) Numerical simulation of wave-current interaction using a RANS solver. Ocean Eng 75:157-164

Zhang R, Liu S, Li J, Zhang H (2019b) Experimental study on pile group effect of a 9-tandem-pile structure under the action of irregular waves. J Waterw Harb 40(1):21-27

Zhang X (2012) Numerical analysis of fluid-structure interaction of wave-current forces on small-scale double-column structures. Highway (5):202-205

Zhu B, Huang B, Kang A, Zhang J (2019) State-of-the-art review of the action of extreme wave (wave-current) on the superstructure of sea-crossing bridges in 2019. J Civil Environ Eng 42(5):1-9

Zhuang X, Li S, Qi Z (2015) Numerical simulation for flow around pile group based on FVM. J Tianjin Univ Sci Technol 48(5): $445-454$

\section{Publisher's Note}

Springer Nature remains neutral with regard to jurisdictional claims in published maps and institutional affiliations.

\section{Submit your manuscript to a SpringerOpen ${ }^{\circ}$ journal and benefit from:}

- Convenient online submission

- Rigorous peer review

- Open access: articles freely available online

- High visibility within the field

- Retaining the copyright to your article

Submit your next manuscript at $\mathbf{s p r i n g e r o p e n . c o m ~}$ 